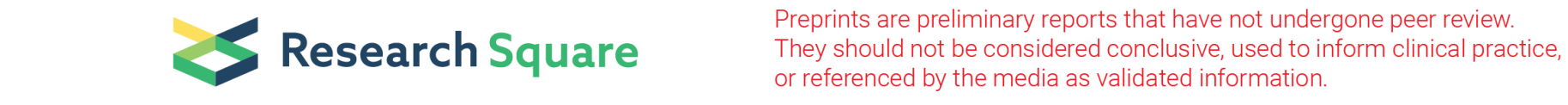

\title{
Vaccine preferences driving vaccine-decision making of different target groups: A systematic review of choice-based experiments
}

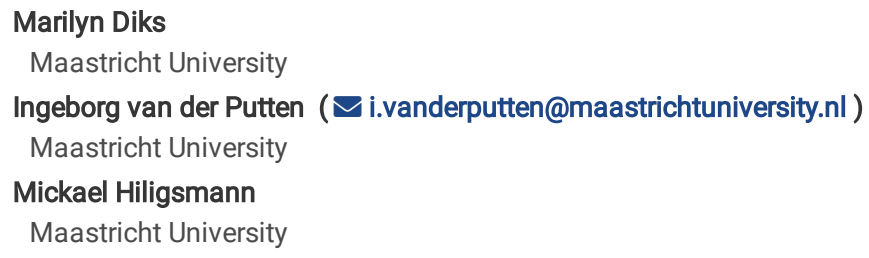

\section{Research Article}

Keywords: Discrete choice experiment, Conjoint analysis, Stated preferences, Vaccine behaviour, Vaccine Decision-Making, Target groups

Posted Date: December 17th, 2020

DOI: https://doi.org/10.21203/rs.3.rs-123374/v1

License: () (1) This work is licensed under a Creative Commons Attribution 4.0 International License. Read Full License 


\section{Abstract}

Background: Choice-based experiments have been increasingly used to elicit preferences for vaccines and vaccination programs. This study aims to systematically identify and examine choice-based experiments assessing (differences in) vaccine preferences of vaccinees, representatives and health advisors.

Methods: Five electronic databases were searched on choice-based conjoint analysis studies or discrete choice experiments capturing vaccine preferences of children, adolescents, parents, adults and healthcare professionals for attributes of vaccines or vaccine settings up to September 2020. Data was extracted using a standardized form covering all important aspects of choice experiments. A quality assessment was used to assess the validity of studies. Attributes were categorized into outcome, process, cost and other attributes. The importance of attributes was assessed by the frequency of reporting and statistical significance. Results were compared between high-quality studies and lower-quality studies.

Results: A total of 42 studies were included, with the majority conducted in high-income countries after 2010 (resp. $n=34$ and n=37). Preferences of representatives were studied in nearly half of the studies $(47.6 \%)$, followed by vaccinees $(35.7 \%)$ and health advisors (9.5\%). Sixteen high-quality studies passed the quality assessment. Outcome- and cost- related attributes such as vaccine effectiveness, vaccine risk, cost and protection duration were most often statistically significant across both target groups, with vaccine effectiveness being the most important. Risks associated with vaccination, such as side effects, were more often statistically significant in studies targeting vaccinees, while cost-related attributes were more often statistically significant in studies of representatives. Process-related attributes such as vaccine accessibility and time were least important across both target groups.

Conclusion: To our knowledge, this is the first systematic review in which vaccine preferences of different target groups were assessed and compared. The same attributes were most important for vaccine decisions of vaccinees and representatives, with only minor differences in level of evidence for vaccine risk and cost. Future research on vaccine preferences of health advisors and/or among target groups in low-resource settings would give insight into the generalizability of current findings.

\section{Background}

Within the last decades, the understanding of vaccine decision-making has been expanded. Vaccine decisions are no longer considered as simple binary decisions, but rather as complex multifaceted decisions taken along a continuum [1,2]. To arrive at a vaccine decision, individuals consider a set of alternatives that are evaluated based on individual needs and interests [3]. Vaccine decisions are, hence, subject to multiple internal and external stimuli, such as personal values $[4,5]$, information sources $[4,6,7]$, social support [8], risk perception, vaccine effectiveness $[5,8]$ and provider trust [4-6]. As a consequence, various (possibly opposing) values may be assigned to characteristics of vaccine alternatives resulting in a wide range of vaccine preferences and decisions. Moreover, health-related preferences depend on whom it is taken for (i.e. the decision-making role) [9]. For vaccination, the decision could either be taken by the vaccinee or someone else. A vaccinee is an individual to whom a vaccine is administered and is often involved in vaccine-decision making. However, vaccinees do not necessarily need to draw the actual vaccine decision, and be the decision-maker [10]. Representatives or health advisors may also be entitled to make the decision for the vaccinee. Parents or guardians decide for instance to vaccinate their child and some vaccinees cede decision authority to their healthcare provider $[9,10]$.

A study of Goldstein \& Weber [11] indicates that individuals apply different strategies when deciding for themselves or someone else. In line with this, Zikmund-Fisher, Sarr, Fagerlin \& Ubel [9] demonstrate substantial variation in treatment preferences between decision-making roles. Medical professionals and parents are for instance more proactive in flu vaccination (i.e. choose to vaccinate) than vaccinees. Additionally, health-related preferences and decisions vary according to the importance of decisions [12]. Particularly in the context of rising vaccine opportunities, global vaccine implementation and the associated rise in vaccine decisions $[13,14]$, the complexity of and variation in vaccine preferences may increasingly affect vaccine uptake. Therefore, it is important to gain insight into vaccine-related behaviour including preference differences between decision-making groups.

With respect to preferences, a distinction is made between revealed preferences (RP) and stated preferences (SP). While RP focus on current vaccine behaviour and analyse observed choices, SP describe hypothetical vaccine decision contexts and are based on the analysis of individual choices (stated behaviour) between hypothetical alternatives. These stated choices are assumed to reflect and comply with decisions in real-life settings and are increasingly applied in health economics to understand the valuation of existing or future vaccines, to forecast (changes in) vaccine behaviour and/or to determine the willingness-to-pay (WTP) for particular alternatives [15-18]. To capture preferences in vaccination, choice-based experiments, such as Discrete Choice Experiments (DCEs) and Conjoint Analyses (CAs), are most often used [19]. Within these experiments individuals are given series of hypothetical vaccine scenarios and asked to choose their preferred scenario from a given choice set (e.g. vaccine A or B) [18]. Each scenario in a choice set is constructed by the same attributes (e.g. vaccine effectiveness, protection duration, side effects), but with varying attribute levels (e.g. effectiveness of $50 \%$ vs. $99 \%$ ). By analysing individuals' responses to changing level of attributes, attribute trade-off information is obtained and the relative importance of attributes as well as the expected vaccine uptake of current and hypothetical vaccines could be estimated [19].

Despite the growing interest in the use of choice-based experiments in vaccination, limited reviews have been conducted on this topic. Moreover, preceding reviews of SP research mainly focused on preferences for specific vaccines (e.g. HPV vaccine) and was usually restricted to High-Income Countries (HICs) [19-21]. Michaels-Igbokwe MacDonald \& Currie [19] published in 2017, for instance, a review on preferences for childhood and adolescent vaccines. However, due to their methodological focus, no conclusions were drawn on vaccine attributes influencing vaccine decisions. Furthermore, no studies nor reviews examined the differences in vaccine preferences between decision-making groups such as vaccinees and representatives. Given the global challenge of vaccine hesitancy [14] and limited effectiveness of policy measures fostering vaccine uptake [23, 24], it is important to gain deeper insight into general preferences for vaccine characteristics as well as differences in vaccine preferences. This will provide an overview of global vaccine preferences and offers the prospect of improving vaccine uptake by creating new and adapting existing policy measures and strategies to the needs of specific target groups. This 
approach, hence, not only fits the life-course approach of the European Commission [25, 26], but also the recommendations of the Strategic Group of Experts on Immunization [14] which stressed the need to understand drivers of vaccine decision-making and implement tailored strategies improving vaccine uptake.

Therefore, this study aims to review, summarize and critically assess studies that used choice-based experiments to measure SP in the field of vaccination. In addition, we aimed to identify vaccine attributes influencing vaccine decision-making of specific target groups (i.e. vaccinees, representatives and health advisors) and to examine differences between vaccine preferences of target groups.

\section{Methods}

\section{Search terms and strategy}

To obtain a comprehensive overview of the current SP literature on vaccine decision-making, a systematic review was conducted. Five electronic databases were searched comprehensively in order to identify published choice-based experiments capturing vaccine preferences. PubMed, EMBASE, Web of Science, EconLit and CINAHL were searched on the following search terms: "vaccin* OR immunis* OR immuniz*" AND "discrete choice OR choice experiment OR DCE OR conjoint analysis OR stated preference" AND "preference". The strategy was adapted from the review of Michaels-lgbokwe et al. [19]. To ensure an optimal search in each of the databases subject headings were used if applicable (MeSH terms in PubMed, Emtree terms in EMBASE and CINAHL subject headings in CINAHL). An overview of the search strategy is included in Additional file 1. The search was limited to articles concerning human vaccines and vaccination programs. Studies who met the following inclusion criteria were included in this review: 1) describing a choice-based conjoint analysis study or a DCE; 2) targeting preferences of children, adolescents, parents, adults and/or healthcare professionals or societal preferences for attributes of vaccines or the setting; 3) original scientific research written in English. Studies without a component of choice, such as approaches focusing exclusively on time trade-off, ranking or best-worst scaling, were hence not eligible for this study. In addition, re-analyses of previously conducted studies were excluded. After the conduct of the search, duplicates were removed manually. Titles and abstracts of all unique articles were then screened for relevance. Subsequently, the eligibility of the remaining articles was determined by reviewing full texts and assessing if the inclusion criteria were met. To supplement and extend the primary search, an additional search based on snowballing was performed after completion of the initial search. Backward and forward snowballing were applied by screening reference lists and citations, of already included studies, on additional studies [27]. Previous reviews on vaccine preferences were also checked for additional studies [17-19, 21, 28, 29], as some used slightly different key words/search terms compared to the adapted search string of Michaels-lgbokwe et al. [19]. The primary and additional search were conducted between April and May 2020. In order to identify eligible studies that were missed during these searches, an update to the review was conducted in September 2020. To assure consistency, the same eligibility criteria were used during all searches. The PRISMA flow diagram was used as a template to report outcomes of both searches and the PRISMA checklist was used as a guideline to draw this report [30].

\section{Assessment of included studies Review of study characteristics}

A standardized form was used to extract data from each included article and subsequently to review the study characteristics. This form was in correspondence with templates used by previous reviews $[19,31]$ and covered topics related to the: a) study characteristics, b) choice task and experimental design, c) conduct, d) analysis, and e) publication and funding. As previous research [19-21] indicated that choice-based experiments use various definitions/terminology for similar attributes, attributes were divided into three overarching categories: outcomes, process and cost. 'Outcomes' referred to the results or consequences of administering vaccines, such as vaccine effectiveness and protection duration. 'Process' incorporated the activities related to the delivery and administration of vaccines and 'cost' covered the (financial) costs of vaccines. Attributes that could not be grouped under the former three categories were classified into a fourth category, named 'other'. Within each of the four categories, attributes with shared features were grouped according to their underlying concept. This implied that subgroups were formed, which were called 'domains' and allowed for a more comprehensive synthesis of results. Data was extracted from all full text articles as well as corresponding supplementary material that was available online. The quality assessment also used both sources of information (see below). The search, data extraction, review of study characteristics, quality assessment and data comparison were conducted by one reviewer (MD). The eligibility of ambiguous studies and study characteristics were discussed with and checked by a second researcher (IvdP). Atlas.ti (version 8.4.4) and spreadsheets of MS Excel were used for both the data extraction and validity assessment.

\section{Assessment of quality}

Prior to the data comparison, the methodological quality of the included studies was critically appraised by using the 13-criteria-checklist of Mandeville Lagarde \& Hanson [31]. This checklist is based on the comprehensive quality checklist of Lancsar \& Louviere [32] and incorporates all key stages DCEs: choice task design, experimental design, conduct and analysis. In addition, it covers the ten steps of producing good conjoint analysis research in healthcare, defined by the International Society for Pharmacoeconomics and Outcomes Research (ISPOR) Good Research Practices for Conjoint Analysis Task Force [33]. Full texts of included studies were appraised by allocating scores to each criterion of the checklist. Three answer options (scores) were possible and depended on the presence of items. A score of 0 was assigned to items that were not satisfied, absent or not reported, 0.5 to items that were partly present or satisfied and 1 to items that were present or satisfied $[19,31]$. The maximum score was 13 and was associated with a high methodological quality. Accordingly, the minimum score of 0 indicated a low methodological quality. Although literature suggests that quality scores often reflect the quality of reporting rather than the quality of the underlying research [33,34], the 13-criteria checklist only included those criteria that threaten the validity of results the most. The developers of the checklist hence assumed that this checklist is appropriate to indicate a study's internal validity. They recommended to restrict the data comparison to studies with a few threats to validity and to apply a quality threshold of 75\% [31]. Based on this recommendation, the same quality threshold (of $75 \%$ ) was used in this review to quality a study of "high-quality". This implies that a quality score of at least 10 (out of 13) was considered sufficient to be included in the data comparison..

\section{Data comparison}


To be able to indicate the relative importance of individual vaccine attributes for specific target groups, a descriptive synthesis was used. The amount of times that particular vaccine attributes (domains) were reported in studies were counted as well as the amount of times domains were reported statistically significant by the authors (incl. p-value threshold or alpha). Generally, main models and overall results were used if available. Subgroups results were used when outcomes were reported for subgroups or classes only (i.e. no overall data). In case a study included multiple attributes related to the same domain (e.g. 'vaccine side effects' and 'risk of dosing' both targeting the domain 'vaccine risk'), statistical significance was reported for each of the attributes separately. This implies that a study could report statistical significance for a single domain more than once.

To ensure a more accurate reflection of domains driving decision-making, the amount of studies reporting statistical significance, for a particular domain, were also stated. In addition, when different p-value thresholds were used in text, tables or figures, the threshold reported in the main text was used. In case no $p$ value threshold was reported but $p$-values were given, the commonly used threshold of $p<0.05$ was used to determine if attributes were statistically significant [35]. The overall frequency as well as the classification of statistically significant attributes/domains were presented in a tabular summary and were reported for each target group. According to Holly, Salmond \& Saimbert [36] this approach will facilitate comparison across studies and enables the identification of underlying causes of heterogeneity.

\section{Comparison of high- and lower-quality studies}

To determine whether exclusion of lower-quality studies influenced or changed findings for any of the target groups (i.e. inferred selection bias), results of only including high-quality studies (quality score $\geq 10$ ) were compared to results of including all eligible studies (full range of quality scores: $0-13$ ). The notion of face validity was used to determine if and to what extend results were accordance with each other. According to Polit \& Beck [37], the use of multiple strategies is the most prudent approach to deal with variation in study quality.

\section{Ethics}

Before the start of the study, a review protocol was drafted and submitted on PROSPERO (ID: 178245). The review was executed as planned/described in the protocol. As this review used primary studies as the unity of subject and included no direct human involvement [36], it did not fall within the ambit of the Dutch Act 'Wet Medisch-Wetenschappelijk Onderzoek met Mensen'. No ethical approval of a Medical Review Ethics Committee was hence needed [38].

\section{Results}

\section{Search results}

In total, 546 records were identified during the primary search. After removal of duplicates, 416 unique records remained and were screened on title and abstract. This resulted in a further removal of 364 records, after which 52 remained left for full-text screening. Reason for removal related to the inappropriateness of the study design, study topic, type of publication (e.g. re-analysis, meeting/conference abstract, erratum) or a combination. During the subsequent searches, two additional articles were obtained (one through snowballing, one through search update). A total of 42 articles were eligible and were included in the review of study characteristics. In addition, 26 articles did not pass the validity assessment as their score was below 10 (see validity assessment). Eventually, sixteen articles were included in the data comparison (Fig. 1).

\section{Review of study characteristics}

Characteristics of all 42 studies were described in this section in order to provide a full overview of the current SP literature on vaccine preferences. A more detailed summary of study characteristics is presented in Additional file 2.

\section{General study characteristics}

Of 42 included choice-based experiments, 31 (73.8\%) applied a DCE format, ten (23.8\%) a CA and one (2.4\%) an Adaptive Discrete Choice Experiment (ADCE). In contrast to DCEs/CAs which use pre-defined attributes, an ADCE allows adaptation of choice scenarios to previous questions. In the study of Ledent et al. [39] respondents were first asked to identify an ideal vaccine scenario to disentangle respondent's preferences for specific attributes. Based on the relative importance and ranking of attributes, tailored scenarios were created for each respondent, which were assumed to approximate actual decision-making (RP) more closely than DCEs [40].

Furthermore, five studies (11.9\%) were published before 2010: two (4.8\%) between 2000-2005 and three (7.1\%) between 2006-2010. Nineteen studies (45.2\%) were published between 2011-2015 and eighteen (42.9\%) between 2016 and September 2020. Included studies were conducted in twenty countries mainly spread across Europe $(n=25)$, Asia $(n=11)$ and North America $(n=8)($ Table 1$)$. More than $80 \%$ was conducted in HICs $(34$ studies) of which the Netherlands and United States of America were most often chosen as study site (resp. 9 and 7 studies). Choice experiments were least performed upper and Low-Middle-Income Countries (LMICs) with respectively five (11.9\%) and two (4.8\%) studies.

Table 1 shows that a variety of vaccines was included. Fourteen different existing vaccines or vaccine programs were studied. Vaccine programs either referred to the administration of a course of vaccines (e.g. all childhood vaccines) or to combination vaccines (e.g. Tdap). Five studies used hypothetical or future vaccines as study topic. Most commonly studied vaccines were HPV and influenza vaccines (resp. 21.4\% and 19.0\%). As previously indicated, this review elicits vaccine preferences of three different target groups. Fifteen of the 42 studies ( $35.7 \%)$ focused on vaccinees, twenty (47.6\%) on representatives and four on health advisors (9.5\%). Three studies (7.1\%) assessed preferences of vaccinees as well as representatives. Marshall, Chen, Clark \& Ratcliffe [41] focussed for instance on adults, parents and adolescents. In approximately half of all studies (expectant) parents, guardians or caregivers were part of the study population (47.6\%), mothers in particular. Nearly all of them targeted representatives (19/20) and specified its population further by defining a child's 
age or phase in life. Three age ranges were broadly used, parents of: infants/toddlers ( $<5$ years), children between $5-10$ years and adolescents ( $>10$ years). These were targeted in respectively nine, three and seven studies. Of the fifteen studies targeting vaccinees, seven studies surveyed the (general) adult population and six studies focused on children and adolescents, especially teenage girls. Preferences of health advisors such as physicians and paediatricians were least captured among included studies (4 studies only).

Table 1 Number of studies per country and vaccine type

\begin{tabular}{ll|ll}
\hline Country & Number of studies (\%)* & Type of vaccine & Number of studies (\%)* \\
\hline Australia & $3(7.1)$ & Childhood (combination) vaccines & $6(14.3)$ \\
Belgium & $1(2.4)$ & General vaccines & $3(7.1)$ \\
\hline Canada & $1(2.4)$ & Hepatitis B (HepB) vaccine & $2(4.8)$ \\
China & $3(7.1)$ & Herpes zoster vaccine & $1(2.4)$ \\
\hline Europe (not specified) & $1(2.4)$ & Human Papilloma Virus (HPV) vaccine & $9(21.4)$ \\
\hline France & $2(4.8)$ & Hypothetical vaccine & $5(11.9)$ \\
\hline Germany & $3(7.1)$ & Influenza vaccine & $1(19.0)$ \\
\hline Hong Kong & $3(7.1)$ & Leptospirosis vaccine & $3(7.1)$ \\
\hline Hungary & $1(2.4)$ & Meningococcal (B) vaccine & $1(2.4)$ \\
\hline Italy & $1(2.4)$ & Pertussis vaccine & $1(2.4)$ \\
\hline Japan & $2(4.8)$ & Pneumococcal vaccine & $2(4.8)$ \\
\hline Netherlands, the & $9(21.4)$ & Rotavirus vaccine & $1(2.4)$ \\
\hline Philippines, the & $1(2.4)$ & Tetanus-Diphtheria-Pertussis (Tdap) vaccine & $1(2.4)$ \\
\hline Poland & $2(4.8)$ & Travel vaccines & $1(2.4)$ \\
\hline South-Africa & $1(2.4)$ & Varicella vaccine & \\
\hline Spain & $2(4.8)$ & & \\
\hline Sweden & $1(2.4)$ & & \\
\hline Thailand & $1(2.4)$ & & \\
\hline United Kingdom & $2(4.8)$ & & \\
\hline Unites States of America & $7(16.7)$ & $1(2.4)$ & \\
\hline Vietnam &
\end{tabular}

*As four studies included more than one country and one study covered multiple vaccines, the total number of studies exceeds the total amount of included studies (and $100 \%$ ).

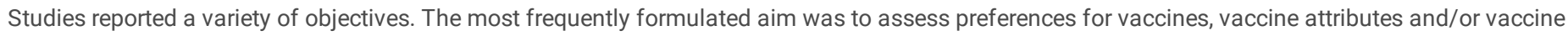

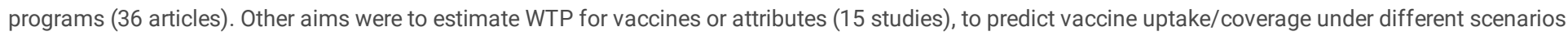

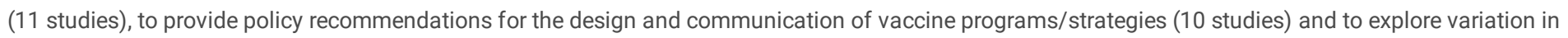

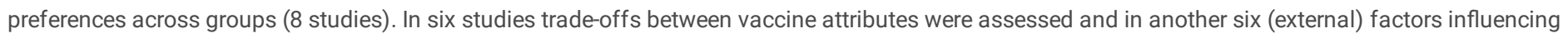

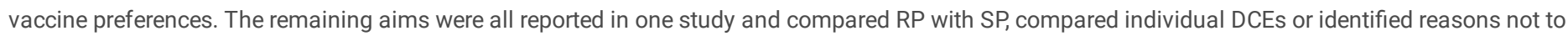

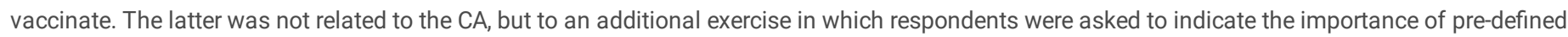
reasons [42].

\section{Choice task}

The number of choice tasks ranged from four to 36 , with most studies (40.5\%) including less than ten choice tasks (Table 2 ). In five studies (11.9\%) the number of choice tasks remained unclear. Each choice task contained one or more scenarios that were characterized by distinct attributes with varying levels. Multiple sources were used to identify appropriate attributes and levels (Table 2). Literature reviews, qualitative research such as focus groups or interviews with the study population and expert consultations were most commonly used (resp. 33, 28 and 19 studies). Experts were either involved in one-on-one interviews or group discussions. Ten studies (23.8\%) used one method, while 31 (73.8\%) used more than one method listed in Table 2. Bishai, Brice, Girod, Saleh \& Ehreth [43] not clearly reported how attributes were identified. A range of approaches was applied to pair and group choice profiles (Table 2). Nearly half of the studies used software packages to create choice sets (43.6\%). Fourteen studies used D-efficiency (35.9\%), which combined choice profiles while minimizing variance and covariance between parameters in the model [44]. In thirteen studies, no details were provided about the way vaccine profiles were combined.

A multinomial choice structure, in which two or more vaccine scenarios were presented per choice task, was used in nearly all studies (92.9\%). Three studies (7.7\%) used a binary choice task and provided a single scenario. The unforced choice with option to remain undecided (opt-out) was most popular among multinomial choice structures (Table 2). Multiple descriptions were used to indicate the opt-out alternative (e.g. 'no vaccination', 'neither'). In two studies the unforced choice was followed by a forced choice without opt-out (two-stage choice). Guo, Zhang, Zhu, Wang \& Shi [45] described this as "If you were actually offered the two vaccines above, which would you prefer to choose?". Adams et al. [46] only provided the forced choice if respondents chose 'neither' at first instance and introduced it by "If vaccination was mandatory". Sixteen studies used a forced choice and asked respondents to choose between two vaccine scenarios without offering an opt-out alternative. Of the studies using this format, twelve studies provided an opt-out in second instance (two-stage choice). Respondents were for instance asked if they would make the same choice in real life [47]. Two studies [48, 49] reported different formats in main texts and example questions.

Table 2 Overview of the design of the choice tasks among included studies 


\begin{tabular}{|c|c|c|}
\hline Aspect & Specification & Number of studies (\%) \\
\hline \multirow{8}{*}{ Methods to identify attributes* } & Characteristics vaccine, disease & $2(4.8)$ \\
\hline & Expert consultation & $19(45.2)$ \\
\hline & Literature review & $33(78.6)$ \\
\hline & Previous DCE & $4(9.5)$ \\
\hline & Qualitative research & $28(66.7)$ \\
\hline & Theories vaccine decision-making & $1(2.4)$ \\
\hline & Vaccination policy & $1(2.4)$ \\
\hline & Not reported & $1(2.4)$ \\
\hline \multirow[t]{2}{*}{ Choice structure } & Binary & $3(7.1)$ \\
\hline & Multinomial & $39(92.9)$ \\
\hline \multirow[t]{7}{*}{ Methods to create choice sets, of multinomial studies $(n=39) * *$} & D-efficiency & $3(7.7)$ \\
\hline & D-efficiency using software & $11(28.2)$ \\
\hline & Fold-over & $3(7.7)$ \\
\hline & Random & $3(7.7)$ \\
\hline & Random using software & $1(2.6)$ \\
\hline & Other software & $5(12.8)$ \\
\hline & Not reported & $13(33.3)$ \\
\hline \multirow{5}{*}{$\begin{array}{l}\text { Format of choice question, } \\
\text { of multinomial studies }(n=39) * *\end{array}$} & Forced choice & $4(10.3)$ \\
\hline & Forced choice, followed by opt-out & $12(30.8)$ \\
\hline & Unforced choice with opt-out & $18(46.2)$ \\
\hline & Unforced choice with opt-out, followed by forced choice & $2(5.1)$ \\
\hline & Unclear & $3(7.7)$ \\
\hline \multirow[t]{4}{*}{ Number of choice tasks } & $<10$ & $17(40.5)$ \\
\hline & $10-15$ & $10(23.8)$ \\
\hline & $>15$ & $10(23.8)$ \\
\hline & Not reported & $5(11.9)$ \\
\hline
\end{tabular}

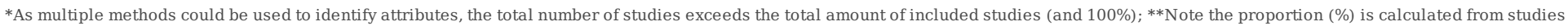
applying multinomial choice structures $(n=39)$, not from the total amount of studies $(n=42)$.

\section{Experimental design}

An overview of the experimental designs used across studies is presented in Table 3. To reduce the number of attribute and level combinations into a more feasible number, a fractional factorial design was used in 35 studies (83.3\%). Only one study (2.4\%) used all possible combinations in a full factorial design and six studies provided no details on its experimental design (14.3\%). Among the studies reporting their type of design, a range of software packages was used, with Ngene being most popular (25.0\%). Eight studies (22.2\%) used approaches other than software such as a catalog or manual approach. Eight studies (22.2\%) not gave insight into the approach or software package used. With regard to the design plan, more than half of the studies (54.8\%) analysed interaction effects along with main effects to assess modification of preferences for vaccine attributes by levels of another. Studies that included interaction terms generally used more choice tasks than the two studies (4.8\%) analysing main effects only. Although seventeen studies (40.5\%) not provided details on their design plan in the main text, primary analyses of thirteen studies showed that it was restricted to main effects.

A total of 226 vaccine attributes were included in the 42 choice experiments. The number of attributes included in a single study varied between three and eight. Most studies included five attributes (11 studies). Attributes were described by varying amounts of levels, ranging from two to seven levels per attribute. With regard to the overarching categories, $38.9 \%$ of the attributes were categorized as outcome, $24.8 \%$ as process, $13.3 \%$ as cost. Among all attributes, $23.0 \%$ could not be grouped under the former three categories and were classified as other. Overall, eighteen domains were identified (3 outcome, 8 process, 1 cost, 7 other). More details on the domains are delineated in the data comparison sections (see below). An overview of attributes included in each domain and category is displayed in Additional file 3.

Table 3 Overview of the experimental design and conduct of included studies 


\begin{tabular}{|c|c|c|}
\hline Aspect & Specification & Number of studies (\%)** \\
\hline \multirow[t]{3}{*}{ Type of design } & Fractional factorial design & $35(83.3)$ \\
\hline & Full factorial design & $1(2.4)$ \\
\hline & Not reported & $6(14.3)$ \\
\hline \multirow[t]{5}{*}{ Design plan } & Main effects & $2(4.8)$ \\
\hline & Main and interaction effects & $23(54.8)$ \\
\hline & Not reported, main effects in primary analysis & $13(31.0)$ \\
\hline & Not reported, main \& interaction effects in primary analysis & $1(2.4)$ \\
\hline & Not reported, unclear in analysis & $3(7.1)$ \\
\hline \multirow[t]{9}{*}{ Software/approach, of studies reporting type of design $(n=36)^{*}$} & Ngene & $9(25.0)$ \\
\hline & SAS & $3(8.3)$ \\
\hline & Sawtooth & $3(8.3)$ \\
\hline & SPSS & $2(5.6)$ \\
\hline & Other computer algorithm & $3(8.3)$ \\
\hline & Catalog approach & 5 (13.9) \\
\hline & Manual & $1(2.8)$ \\
\hline & Other approach & $2(5.6)$ \\
\hline & Not reported & $8(22.2)$ \\
\hline \multirow[t]{3}{*}{ Piloting } & Yes & $34(81.0)$ \\
\hline & No & $1(2.4)$ \\
\hline & Not reported & $7(16.7)$ \\
\hline \multirow[t]{4}{*}{ Mode of administration } & Interview-administered & $5(11.9)$ \\
\hline & Self-administered & $34(81.0)$ \\
\hline & Both & $1(2.4)$ \\
\hline & Not reported & $2(4.8)$ \\
\hline \multirow[t]{7}{*}{ Sample size } & $<200$ & $1(2.4)$ \\
\hline & $200-400$ & $14(33.3)$ \\
\hline & $400-600$ & $12(28.6)$ \\
\hline & $600-800$ & $6(14.3)$ \\
\hline & $800-1000$ & $2(4.8)$ \\
\hline & $1000-1200$ & $1(2.4)$ \\
\hline & $\geq 1200$ & $6(14.3)$ \\
\hline \multirow[t]{3}{*}{ (Financial) compensation } & Yes & $15(35.7)$ \\
\hline & No & $2(4.8)$ \\
\hline & Not reported & $25(59.5)$ \\
\hline
\end{tabular}

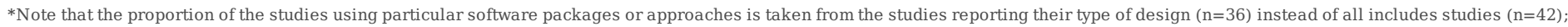
** Due to rounding of percentages, the total may not count up to $100 \%$.

\section{Conduct}

More than three quarters of the studies (81.0\%) reported a pilot and/or soft launch in a small sample before initiation of the survey (Table 3 ). In the study of Hofman, de Bekker-Grob, Richardus, de Koning, Van Ballegooijen \& Korfage [50] no pilot was conducted, as the survey had been pilot tested in a previous DCE addressing the same population. In the remaining studies (16.7\%) it was unclear whether a pilot was performed. The size of pilots differed from performing telephone interviews with four respondents [51] to testing the survey among three hundred respondents [52] and from conducting a single-stage procedure [48] to the use of multiple-stage procedures (e.g. combination of pre-pilot, pilot and soft launches) [46, 53]. Included studies reported two modes of administration and were either interview-administered (11.9\%) or self-administered (81.0\%). In the study of Liao, $\mathrm{Ng}$ and Cowling [54] participants could choose whether they preferred a web-based or in-person survey. The majority of self-administered surveys was completed online (25 studies). Sample sizes ranged from fifty [55] to 2505 in the study of Marshall et al. [41]. Most studies included between two and four hundred respondents (Table 3). Larger sample sizes were not necessarily accompanied by the use of stricter thresholds (e.g. $p<0.001)$. Justification of sample sizes was included in 21 studies $(50.0 \%)$, of which nineteen used a rule of thumb and two used power or sample size calculations. The rule of thumb proposed by Orme [56] was most often used in CAs. The remaining 21 studies $(50.0 \%)$ not justified their sample size nor included sample size calculations. In total, fifteen studies (35.7\%) provided a compensation for participation in cash, giftcards/vouchers or a physical gift such as a blanket. The value of rewards varied from $£ 1-2$ to $\$ 55$. The majority of the studies ( $64.3 \%)$ not compensated respondents or at least not reported it (Table 3).

\section{Analysis}

A summary of the approaches used to analyse data is presented in Table 4. Half of the included studies (50.0\%) applied mixed or random parameter logit models (MXL/RPL), which accounted for the panel nature of data and preference heterogeneity [57]. Multinomial or conditional logit models (MNL/CML) were used in approximately a quarter $(28.6 \%)$ of the included studies. Other estimation procedures commonly used in multinomial choice structures were latent class models (LCM) and hierarchical Bayes estimations. Random or mixed effects logit models were most often used to analyse forced choices. Furthermore, nearly all studies $(41 / 42,97.6 \%)$ accounted for variation in preferences across groups. Subgroup analyses were either performed by using separate models for different groups or by incorporating interaction terms into the model. Characteristics of respondents were most often used to distinguish subgroups. As outlined in Table 4 these characteristics covered a variety of aspects (e.g. demographics, health status). In more than two-third of the studies (69.0\%) subgroups related to a study's methodology. These studies distinguished for instance multiple panels/classes or used different cost ranges, risk information formats and/or informative videos for subgroups within sample. The methodological focus could also refer to the comparison of groups who passed and failed consistency/dominance tests and groups with and without preference to opt-out. Note that 12 studies who used methodological reasons applied more than one method.

With regard to the outcome measures, welfare measures such as WTP were most frequently used (45.2\%), followed by probability or uptake analyses (42.9\%). In the latter vaccine uptake or acceptance was estimated for different vaccine scenarios. Marginal rates of substitution and odds ratio or change in log odds were both reported in eight studies (19.0\%). The former reflected respondents' willingness to trade one level of a particular vaccine attribute for an improved level of another. The latter indicated how (much more or less) likely respondents were to choose a given vaccine scenario defined by a particular attribute level, 
while all other attribute levels remained the same (i.e. constant). Least reported measures were market simulations (combined with or without revenue calculations), willingness-to-accept and positive or negative predictive value (to compare estimated individual utilities with actual behaviour). Moreover, 35 of the 42 studies (83.3\%) reported to have analysed data by using one or multiple software package(s). These packages were not necessarily the same as the ones used to construct experimental designs (e.g. Ngene vs. Nlogit in Hofman et al. [50]). SAS and State were most frequently used (11 studies).

\section{Journal \& funding}

The majority of the studies (25/42,59.5\%) were published in clinical journals. Thereafter, six studies (14.3\%) were published in health economic journals and four (9.5\%) in general journals. Studies were least published in pharmaceutical and marketing journals and ones focusing on methodological approaches in healthcare research (all in 1/42, 2.4\%). Of the 39 studies reporting their source of funding, approximately a quarter was funded or supported by a pharmaceutical or manufacturing company producing the vaccine under study (11 studies). The remaining studies, except for Ngorsuraches et al. [56], received a research grant of governmental bodies, health-related foundations, non-profit organizations or research/education institutes.

Table 4 Overview of approaches used to analyse data

\begin{tabular}{|c|c|c|}
\hline Aspect & Specification & Number of studies (\%)* \\
\hline \multirow[t]{7}{*}{ Econometric model } & Multinomial logit & $12(28.6)$ \\
\hline & Generalized linear random effects logit & $1(2.4)$ \\
\hline & Hierarchical Bayes & $6(14.3)$ \\
\hline & Latent class & $4(9.5)$ \\
\hline & Random effects logit & $6(14.3)$ \\
\hline & Mixed logit (random parameter) & $21(50.0)$ \\
\hline & Other & $5(11.9)$ \\
\hline \multirow[t]{7}{*}{ Subgroup analysis } & Methodology related & $29(69.0)$ \\
\hline & Previous experiences & $5(11.9)$ \\
\hline & Sociodemographic factor(s) & $32(76.2)$ \\
\hline & Vaccine beliefs/perception/knowledge & $13(31.0)$ \\
\hline & Vaccine intention or behaviour & $6(14.3)$ \\
\hline & Vaccination or health status & $5(11.9)$ \\
\hline & Other & $5(11.9)$ \\
\hline \multirow[t]{7}{*}{ Outcome measure } & Individual utility scores & $3(7.1)$ \\
\hline & Odds ratio, change in log-odds & $8(19.0)$ \\
\hline & Relative attribute importance & $10(23.8)$ \\
\hline & Marginal rate of substitution (trade-off) & $8(19.0)$ \\
\hline & Vaccine uptake/probability analysis & $18(42.9)$ \\
\hline & WTP & $19(45.2)$ \\
\hline & Other & $4(9.5)$ \\
\hline \multirow[t]{8}{*}{ Analysis software } & JMP Pro & $2(4.8)$ \\
\hline & Nlogit & $9(21.4)$ \\
\hline & SAS & $11(26.2)$ \\
\hline & Sawtooth & $4(9.5)$ \\
\hline & SPSS & $3(7.1)$ \\
\hline & Stata & $11(26.2)$ \\
\hline & Other & $10(23.8)$ \\
\hline & Not reported & 7 (16.7) \\
\hline
\end{tabular}

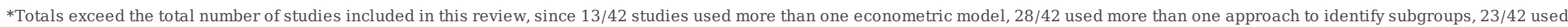
more than one outcome measure, 10/42 used more than one software package.

\section{Quality assessment}

An overview of the quality scores of all 42 studies is presented in Table 5. Quality scores ranged from 5.5 to 12.5 , with an average score of 9.3. Scores did not improve over time, since average scores of studies published between 2000-5, 2006-10, 2011-5 and 2016-20 were 8.8, 10.5, 9.1 and 9.4 respectively. However, industry-funded studies scored lower than non-industry funded studies (mean of resp. 8.5 and 9.5). Among the four categories distinguished in Table 5, studies scored best on the category analysis (mean: 0.84), followed by choice task design (mean: 0.70), conduct (mean: 0.65) and experimental design (mean: 0.55).

Table 5 Overview of the quality assessment of the included studies 


\begin{tabular}{|c|c|c|c|c|c|c|c|c|c|c|c|c|c|c|c|c|c|c|}
\hline \multirow{2}{*}{\multicolumn{2}{|c|}{ Criteria }} & \multicolumn{17}{|l|}{ Study } \\
\hline & & $\begin{array}{l}\text { Adams } \\
\text { et al. } \\
\text { [46] }\end{array}$ & $\begin{array}{l}\text { Arbiol } \\
\text { et al. } \\
\text { [57] }\end{array}$ & $\begin{array}{l}\text { Bishai } \\
\text { et al } \\
\text { [43] }\end{array}$ & $\begin{array}{l}\text { Brown } \\
\text { et al. } \\
\text { [48] }\end{array}$ & $\begin{array}{l}\text { Brown } \\
\text { et al. } \\
\text { [49] }\end{array}$ & $\begin{array}{l}\text { de } \\
\text { Bekker- } \\
\text { Grob et } \\
\text { al. [58] }\end{array}$ & $\begin{array}{l}\text { de } \\
\text { Bekker- } \\
\text { Grob et } \\
\text { al. [52] }\end{array}$ & $\begin{array}{l}\text { Determann } \\
\text { et al. [59] }\end{array}$ & $\begin{array}{l}\text { Determann } \\
\text { et al. [60] }\end{array}$ & $\begin{array}{l}\text { Eilers } \\
\text { et al. } \\
\text { [61] }\end{array}$ & $\begin{array}{l}\text { Flood } \\
\text { et al. } \\
\text { [62] }\end{array}$ & $\begin{array}{l}\text { Flood } \\
\text { et al. } \\
\text { [63] }\end{array}$ & $\begin{array}{l}\text { Gidengil } \\
\text { et al. } \\
\text { [64] }\end{array}$ & $\begin{array}{l}\text { Guo } \\
\text { et } \\
\text { al. } \\
\text { [45] }\end{array}$ & $\begin{array}{l}\text { Hall } \\
\text { et } \\
\text { al. } \\
\text { [55] }\end{array}$ & $\begin{array}{l}\text { Hofman } \\
\text { et al. } \\
\text { [65] }\end{array}$ & $\begin{array}{l}\text { Hofman } \\
\text { et al. } \\
\text { [50] }\end{array}$ \\
\hline \multirow[t]{3}{*}{$\begin{array}{l}\text { Choice } \\
\text { task } \\
\text { design }\end{array}$} & $\begin{array}{l}\text { Attributes } \\
\text { and levels } \\
\text { grounded in } \\
\text { qualitative } \\
\text { work with } \\
\text { target } \\
\text { population }\end{array}$ & 1 & 0 & 0 & 1 & 1 & 0.5 & 1 & 1 & 1 & 0.5 & 1 & 1 & 0.5 & 0 & 0 & 1 & 0 \\
\hline & $\begin{array}{l}\text { No conceptual } \\
\text { overlap } \\
\text { between } \\
\text { attributes }\end{array}$ & 0 & 1 & 1 & 0.5 & 0.5 & 0.5 & 0.5 & 1 & 1 & 0.5 & 0.5 & 0.5 & 0.5 & 1 & 0.5 & 1 & 1 \\
\hline & $\begin{array}{l}\text { Uni- } \\
\text { dimensional } \\
\text { attributes }\end{array}$ & 0.5 & 1 & 1 & 1 & 1 & 1 & 1 & 1 & 1 & 0.5 & 1 & 1 & 0.5 & 1 & 0.5 & 1 & 1 \\
\hline $\begin{array}{l}\text { Experimental } \\
\text { design }\end{array}$ & $\begin{array}{l}\text { Experimental } \\
\text { design } \\
\text { optimal or } \\
\text { statistically } \\
\text { efficient } \\
\end{array}$ & 1 & 0.5 & 0.5 & 1 & 1 & 1 & 1 & 1 & 1 & 0 & 0 & 0 & 0 & 0.5 & 0.5 & 1 & 1 \\
\hline \multirow[t]{3}{*}{ Conduct } & $\begin{array}{l}\text { Piloting } \\
\text { conducted } \\
\text { amongst } \\
\text { target } \\
\text { population } \\
\end{array}$ & 1 & 0.5 & 0 & 1 & 1 & 0.5 & 1 & 0.5 & 0.5 & 1 & 0.5 & 0 & 0.5 & 0 & 0 & 0.5 & 0.5 \\
\hline & $\begin{array}{l}\text { Target } \\
\text { population(s) } \\
\text { appropriate } \\
\text { for research } \\
\text { objective }\end{array}$ & 1 & 1 & 1 & 1 & 1 & 1 & 1 & 1 & 1 & 1 & 1 & 1 & 1 & 1 & 1 & 1 & 1 \\
\hline & $\begin{array}{l}\text { Response rate } \\
\text { sufficient to } \\
\text { minimize } \\
\text { response bias }\end{array}$ & 0 & 0 & 0 & 0.5 & 0.5 & 1 & 1 & 0.5 & 0.5 & 0.5 & 0.5 & 0.5 & 0.5 & 1 & 1 & 0.5 & 1 \\
\hline \multirow[t]{4}{*}{ Analysis } & $\begin{array}{l}\text { Any pooled } \\
\text { analysis from } \\
\text { different } \\
\text { subgroups } \\
\text { appropriate } \\
\end{array}$ & 1 & 1 & 1 & 0.5 & 1 & 1 & 1 & 1 & 1 & 1 & 0 & 0 & 1 & 0.5 & 1 & 0.5 & 1 \\
\hline & $\begin{array}{l}\text { Econometric } \\
\text { model } \\
\text { appropriate } \\
\text { for choice task } \\
\text { design } \\
\end{array}$ & 1 & 1 & 1 & 1 & 1 & 1 & 1 & 1 & 1 & 1 & 0.5 & 0.5 & 0.5 & 1 & 1 & 1 & 1 \\
\hline & $\begin{array}{l}\text { Econometric } \\
\text { model } \\
\text { accounts for } \\
\text { serial } \\
\text { correlation of } \\
\text { choices }\end{array}$ & 1 & 1 & 1 & 1 & 1 & 1 & 1 & 1 & 1 & 1 & 0 & 0 & 1 & 1 & 1 & 1 & 1 \\
\hline & $\begin{array}{l}\text { Relative } \\
\text { attribute } \\
\text { effects } \\
\text { compared } \\
\text { using a } \\
\text { common } \\
\text { metric }\end{array}$ & 1 & 1 & 1 & 1 & 1 & 1 & 1 & 1 & 1 & 0 & 0 & 0 & 1 & 1 & 1 & 1 & 1 \\
\hline \multicolumn{2}{|c|}{ Total validity score } & 10 & 9.5 & 9 & 11 & 11 & 11.5 & 12.5 & 12 & 12 & 8.5 & 5.5 & 5.5 & 8.5 & 9.5 & 8.5 & 11.5 & 11.5 \\
\hline
\end{tabular}

Table 5 Overview of the quality assessment of the included studies (continued) 


\begin{tabular}{|c|c|c|c|c|c|c|c|c|c|c|c|c|c|c|c|c|c|c|}
\hline \multicolumn{2}{|l|}{ Validity criteria } & \multicolumn{17}{|l|}{ Study } \\
\hline & & \multirow{2}{*}{ 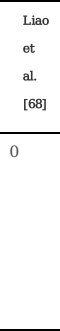 } & \multirow{2}{*}{ 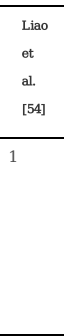 } & \multirow{2}{*}{$\begin{array}{l}\begin{array}{l}\text { Lloyd } \\
\text { et al. } \\
\text { [51] }\end{array} \\
1\end{array}$} & \multirow{2}{*}{$\begin{array}{l}\begin{array}{l}\text { Marshall } \\
\text { et al. }\end{array} \\
\text { [41] } \\
0\end{array}$} & $\begin{array}{l}\text { Ngorsuraches } \\
\text { et al. [56] }\end{array}$ & $\begin{array}{l}\text { Oteng } \\
\text { et al. } \\
\text { [69] }\end{array}$ & $\begin{array}{l}\text { Pereira } \\
\text { et al. } \\
{[70]}\end{array}$ & $\begin{array}{l}\text { Poulos } \\
\text { et al. } \\
\text { [71] }\end{array}$ & $\begin{array}{l}\text { Poulos } \\
\text { et al. } \\
\text { [72] }\end{array}$ & $\begin{array}{l}\text { Poulos } \\
\text { et al. } \\
{[42]}\end{array}$ & $\begin{array}{l}\text { Poulos } \\
\text { et al. } \\
\text { [53] }\end{array}$ & $\begin{array}{l}\text { Sadique } \\
\text { et al. } \\
\text { [73] }\end{array}$ & $\begin{array}{l}\text { Sapòde } \\
\text { et al. } \\
\text { [74] }\end{array}$ & $\begin{array}{l}\text { Seanehia } \\
\text { et al. [75] }\end{array}$ & $\begin{array}{l}\text { Shono } \\
\text { et al. } \\
\text { [76] }\end{array}$ & $\begin{array}{l}\text { Shono } \\
\text { et al. } \\
\text { [77] }\end{array}$ & $\begin{array}{l}\text { Sun } \\
\text { et } \\
\text { al. } \\
\text { [78] }\end{array}$ \\
\hline $\begin{array}{l}\text { Choice } \\
\text { task } \\
\text { design }\end{array}$ & $\begin{array}{l}\text { Attributes } \\
\text { and levels } \\
\text { grounded in } \\
\text { qualitative } \\
\text { work with } \\
\text { target } \\
\text { population } \\
\end{array}$ & & & & & 0 & 0.5 & 0.5 & 0 & 0 & 1 & 0.5 & 0 & 1 & 0 & 0 & 0 & 1 \\
\hline & $\begin{array}{l}\text { No conceptual } \\
\text { overlap } \\
\text { between } \\
\text { attributes }\end{array}$ & 0.5 & 0 & 0.5 & 1 & 0.5 & 0.5 & 0.5 & 0.5 & 0.5 & 1 & 1 & 0 & 1 & 1 & 1 & 1 & 0.5 \\
\hline & $\begin{array}{l}\text { Uni- } \\
\text { dimensional } \\
\text { attributes } \\
\end{array}$ & 1 & 1 & 1 & 0.5 & 1 & 1 & 1 & 1 & 0.5 & 0.5 & 1 & 0 & 1 & 1 & 1 & 1 & 1 \\
\hline $\begin{array}{l}\text { Experimental } \\
\text { design }\end{array}$ & $\begin{array}{l}\text { Experimental } \\
\text { design } \\
\text { optimal or } \\
\text { statistically } \\
\text { efficient } \\
\end{array}$ & 0.5 & 0.5 & 0.5 & 0.5 & 0.5 & 0.5 & 0.5 & 1 & 1 & 0 & 0 & 0 & 0 & 0.5 & 0.5 & 0.5 & 0 \\
\hline \multirow[t]{3}{*}{ Conduct } & $\begin{array}{l}\text { Piloting } \\
\text { conducted } \\
\text { amongst } \\
\text { target } \\
\text { population } \\
\end{array}$ & 0.5 & 0.5 & 1 & 1 & 0.5 & 0.5 & 0 & 1 & 1 & 1 & 0.5 & 1 & 0.5 & 1 & 0.5 & 0.5 & 0 \\
\hline & $\begin{array}{l}\text { Target } \\
\text { population(s) } \\
\text { appropriate } \\
\text { for research } \\
\text { objective } \\
\end{array}$ & 0.5 & 0.5 & 1 & 1 & 1 & 0.5 & 1 & 1 & 1 & 1 & 1 & 1 & 0.5 & 1 & 1 & 1 & 0.5 \\
\hline & $\begin{array}{l}\text { Response rate } \\
\text { sufficient to } \\
\text { minimize } \\
\text { response bias } \\
\end{array}$ & 0 & 0 & 0 & 0 & 1 & 0 & 0 & 0.5 & 0 & 0.5 & 0 & 0 & 0 & 0 & 0 & 0 & 1 \\
\hline \multirow[t]{4}{*}{ Analysis } & $\begin{array}{l}\text { Any pooled } \\
\text { analysis from } \\
\text { different } \\
\text { subgroups } \\
\text { appropriate } \\
\end{array}$ & 1 & 1 & 1 & 1 & 1 & 1 & 1 & 1 & 1 & 1 & 1 & 0 & 1 & 0.5 & 1 & 1 & 0.5 \\
\hline & $\begin{array}{l}\text { Econometric } \\
\text { model } \\
\text { appropriate } \\
\text { for choice task } \\
\text { design } \\
\end{array}$ & 1 & 1 & 0 & 1 & 0.5 & 1 & 0.5 & 1 & 1 & 1 & 0.5 & 1 & 1 & 1 & 1 & 1 & 0.5 \\
\hline & \begin{tabular}{|l} 
Econometric \\
model \\
accounts for \\
serial \\
correlation of \\
choices \\
\end{tabular} & 1 & 1 & 0 & 1 & 0 & 1 & 1 & 1 & 1 & 1 & 0 & 1 & 1 & 1 & 0 & 1 & 1 \\
\hline & $\begin{array}{l}\begin{array}{l}\text { Relative } \\
\text { attribute }\end{array} \\
\text { effects } \\
\text { compared } \\
\text { using a } \\
\text { common } \\
\text { metric } \\
\end{array}$ & 0.5 & 0.5 & 1 & 1 & 0.5 & 1 & 1 & 1 & 1 & 1 & 1 & 1 & 1 & 1 & 1 & 1 & 1 \\
\hline \multicolumn{2}{|c|}{ Total validity score } & 8 & 8 & 7 & 10 & 8 & 9.5 & 8 & 11 & 10 & 11 & 8 & 7 & 9 & 9.5 & 9 & 10 & 8 \\
\hline
\end{tabular}

With respect to the category choice task design, the majority of the studies used unidimensional attributes and included an opt-out in first or second instance (resp. $71.4 \%$ and $73.8 \%$ ). However, weaknesses were particularly observed in the identification of attributes/levels and in the occurrence of conceptual overlap between attributes. The second category, experimental design, was comprised of one criterion. For this criterion it was observed that the majority of the studies $(64.3 \%)$ used (fractional) factorial designs that were sub-optimal (i.e. scored below 1). This indicated room for improvement. Furthermore, varying scores were administered on the criteria incorporated in the conduct category. While studies commonly tested survey features in a pilot and identified appropriate target populations, three-quarter reported response rates below $50 \%$ and almost half used inappropriate sampling frames. The last category referred to the analysis. Almost all studies satisfied at least three of the four criteria incorporated in this category, particularly the ones concerning the economic model and the use of 
a common comparable scale (metric) to interpret relative attribute effects $[32,83]$. Some improvements could still be made in analysis of preferences of heterogenous populations, as pooled data might cover up preference differences between subgroups [31, 32].

When combining scores on the four categories into an overall score, sixteen of the 42 studies (38.1\%) had a total score of at least 10 and passed the quality assessment (Fig. 1). These were regarded as 'high-quality studies' and were included in the data comparison. Total scores of the remaining studies (61.9\%) were insufficient to exclude most threats to validity (score < 10). These 'lower-quality studies' were hence only included in the robustness analyses. A more detailed description of the quality assessment is enclosed in Additional file 4.

\section{Comparison of high-quality studies}

Of the sixteen high-quality studies, seven studies focused on vaccinees (43.8\%) and six on representatives (37.5\%). The study of Poulos, Reed Johnson, Krishnarajah, Anonychuk \& Misurski [72] was the only study capturing preferences of health advisors (6.3\%). As it is difficult to draw firm conclusions on a single study, this study was added to the representatives' category. Two studies addressed vaccine preferences for vaccinees as well as representatives (12.5\%). As both studies reported preferences for vaccinees and representatives separately (per class), classes covering vaccinees were incorporated into the analysis of vaccinees and classes covering representatives were used for analysing preferences of representatives. Therefore, data of nine studies was compared for both target groups. A summary of the information on vaccine attributes of high-quality studies is outlined in Additional file 5.

\section{Vaccinees}

Studies capturing preferences of vaccinees used 48 attributes, of which $50 \%$ were classified as outcome, $16.7 \%$ as process, $10.4 \%$ as cost and the remaining $22.9 \%$ as other. Thirteen domains were identified in total (three outcome, four process, one cost and five other). Figure 2 presents the total amount of attributes incorporated in each domain and category. Importance rankings derived from this figure are outlined in Additional file 6 . The most frequently used outcome measures were vaccine effectiveness and vaccine risk (both 18.8\%), followed by protection duration (12.5\%). Cost, disease risk and dosing \& visits were used in $10.4 \%, 6.3 \%$ and $6.3 \%$ of the studies. They covered respectively cost, other and process-related categories. Context, information, other disease related factors, vaccine advice/support were also reported, but could not be grouped in any of the three categories. They are classified as other. 'Context' referred to vaccine coverage rates at local and population level, 'information' to the media coverage or attention about the vaccine and 'vaccine advice/support' to recommendations of family, friends, doctors, governmental bodies and international organizations. Process-related domains were least reported. Vaccine accessibility was for instance only included in the study of Verelst, Willem, Kessels \& Beutels (2.1\%) [80]. Statistical significance was reported in all nine studies. These studies had an average sample size of 1113 respondents and used three p-value thresholds to determine if attribute domains were statistically significant (Table 6). Vaccine risk and vaccine effectiveness, both outcome measures, were most often statistically significant (resp. 15 and 14 times). However, the latter was not found to be significant for one class of the study of Determann et al. [60]. Domains that were also commonly statistically significant included: cost, protection duration, dosing \& visits, information and vaccine advice or support. The importance of the former three was also confirmed in the frequency of reporting (Fig. 2). Factors other than disease risk, such as the spread of the disease and availability of curative treatments, were grouped under the domain 'other disease related factors' (category: other). This domain as well as the domain 'time' (process) were not statistically significant in any of the studies.

Table 6 Overview of high-quality studies reporting relative statistical significance (vaccinees)

\begin{tabular}{|c|c|c|c|c|c|}
\hline \multirow[t]{2}{*}{ Category \& domain $(\mathrm{n}=)^{*}$} & \multicolumn{5}{|c|}{ Statistical significance** } \\
\hline & $P<0.10$ & $P<0.05$ & $P<0.01$ & Total & Not significant \\
\hline \multicolumn{6}{|l|}{ Outcome } \\
\hline Protection duration $(n=6)$ & 0 & 3 & 5 & 8 & 1 \\
\hline Vaccine effectiveness $(n=8)$ & 0 & 5 & 9 & 14 & 1 \\
\hline Vaccine risk $(\mathrm{n}=7)$ & 0 & 4 & 11 & 15 & 0 \\
\hline \multicolumn{6}{|l|}{ Process } \\
\hline Dosing $\&$ visits $(\mathrm{n}=3)$ & 1 & 1 & 3 & 5 & 1 \\
\hline Time $(\mathrm{n}=2)$ & 0 & 0 & 0 & 0 & 2 \\
\hline Vaccination age $(n=2)$ & 0 & 1 & 2 & 2 & 1 \\
\hline Vaccine accessibility $(\mathrm{n}=1)$ & 0 & 1 & 0 & 1 & 0 \\
\hline \multicolumn{6}{|l|}{ Cost } \\
\hline Cost $(n=5)$ & 0 & 1 & 8 & 9 & 0 \\
\hline \multicolumn{6}{|l|}{ Other } \\
\hline Context $(\mathrm{n}=1)$ & 0 & 2 & 0 & 2 & 0 \\
\hline Disease risk $(n=2)$ & 0 & 1 & 2 & 3 & 0 \\
\hline Information $(\mathrm{n}=2)$ & 1 & 1 & 3 & 5 & 0 \\
\hline Other disease related factors $(n=1)$ & 0 & 0 & 0 & 0 & 2 \\
\hline Vaccine advice/support $(\mathrm{n}=2)$ & 1 & 0 & 4 & 5 & 0 \\
\hline
\end{tabular}

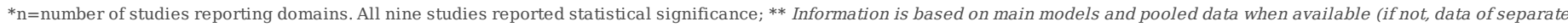
models/classes was used). Some studies included more than one attribute related to a particular domain. Totals could hence exceed the total number of studies incorporated.

\section{Representatives}

In total, 48 attributes were identified in nine studies capturing vaccine preferences of representatives (Fig. 2). Of these attributes, 37.5\% were outcome-related, $31.3 \%$ were process-related and $16.7 \%$ were cost-related. The remaining $11.6 \%$ of the attributes were categorized as other. Overall, fifteen domains were identified (three outcome, seven process, one cost, four other). In contrast to vaccinees, attributes regarding vaccine advice or support were not reported. However, three process-related domains were added: service delivery, target group and vaccine administration. 'Service delivery' covered practical aspects such as vaccine location and availability of appointments, while 'vaccine administration' referred to the mode of administration (e.g. injection). Vaccine effectiveness was most frequently reported (18.8\%), followed by cost (16.7\%), dosing \& visits (12.5\%), vaccine risk (10.4\%) and protection duration ( $8.3 \%)$. 
These domains were respectively outcome-, cost-, process-, outcome-, and outcome-related. In line with studies targeting vaccinees, vaccine accessibility was least reported. Two studies [42, 72] not reported statistical significance or provided no legend (description). For the study of Shono \& Kondo [77], statistical significance could be determined based on reported p-values. Therefore, seven studies were included in Table 7. The average amount of respondents was 1037 and among the four thresholds used, $p<0.05$ was most commonly applied. All attributes included in high-quality studies were statistically significant in one or more study/studies. In line with the frequency of reporting, vaccine effectiveness and cost were most commonly statistically significant, followed by vaccine risk and protection duration. Domains that were least used were also least reported statistically significant. These were categorized as process and other. Varying results were reported for information (other) and service delivery (process) in the study of Adams et al. [46]. The professional administering vaccines was for instance statistically significant, while the availability of appointments and location were not. Service delivery was, hence, more often not statistically significant than significant. Information was found to be statistically significant half of the times, as information on benefits and risks were statistically significant, but the format was not.

Table 7 Overview of high-quality studies reporting relative statistical significance (representatives)

\begin{tabular}{|c|c|c|c|c|c|c|}
\hline \multirow[t]{2}{*}{ Category \& domain $(\mathrm{n}=)^{*}$} & \multicolumn{6}{|c|}{ Statistical significance** } \\
\hline & $\mathrm{P}<0.10$ & $P<0.05$ & $P<0.01$ & $\mathrm{P}<0.001$ & Total & Not significant \\
\hline \multicolumn{7}{|l|}{ Outcome } \\
\hline Protection duration $(\mathrm{n}=4)$ & 0 & 1 & 2 & 1 & 4 & 1 \\
\hline Vaccine effectiveness $(n=6)$ & 0 & 3 & 3 & 1 & 7 & 0 \\
\hline Vaccine risk $(\mathrm{n}=5)$ & 1 & 4 & 0 & 0 & 5 & 0 \\
\hline \multicolumn{7}{|l|}{ Process } \\
\hline Dosing \& visits $(\mathrm{n}=2)$ & 0 & 1 & 1 & 0 & 2 & 0 \\
\hline Service delivery $(\mathrm{n}=2)$ & 0 & 1 & 0 & 0 & 1 & 2 \\
\hline Target group $(\mathrm{n}=1)$ & 0 & 0 & 1 & 0 & 1 & 0 \\
\hline Time $(n=1)$ & 0 & 0 & 1 & 0 & 1 & 0 \\
\hline Vaccination age $(n=1)$ & 0 & 1 & 0 & 0 & 1 & 0 \\
\hline Vaccine accessibility $(\mathrm{n}=1)$ & 0 & 1 & 0 & 0 & 1 & 0 \\
\hline \multicolumn{7}{|l|}{ Cost } \\
\hline Cost $(n=5)$ & 0 & 1 & 4 & 1 & 6 & 0 \\
\hline \multicolumn{7}{|l|}{ Other } \\
\hline Context $(\mathrm{n}=1)$ & 0 & 2 & 0 & 0 & 2 & 0 \\
\hline Disease risk $(\mathrm{n}=1)$ & 0 & 1 & 0 & 0 & 1 & 0 \\
\hline Information $(\mathrm{n}=1)$ & 0 & 0 & 1 & 0 & 1 & 1 \\
\hline
\end{tabular}

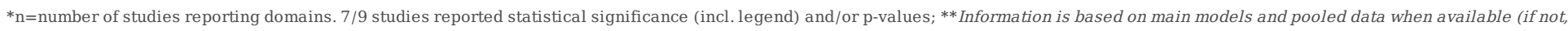

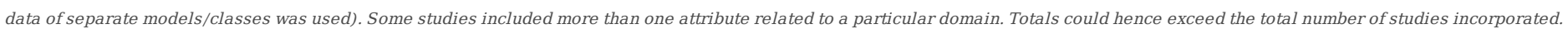

\section{Overall preferences and comparison of vaccinees and representatives}

A total of 96 attributes were identified in high-quality studies. With respect to the four categories, attributes were most commonly classified as outcome $(43.8 \%)$, followed by process $(24.0 \%)$, other (18.8\%) and cost (13.5\%). In addition, these attributes covered sixteen domains. Figure 2 showed that the same domains were valued by vaccinees and representatives. The outcome measure vaccine effectiveness was most often preferred regardless target group. The order of the remaining domains showed slight differences (Additional file 6). Vaccine risk as well as duration of protection (both outcome-related), were for instance more important for vaccinees compared to representatives, while representatives valued costs of vaccines and dosing \& visits more than vaccinees (cost and process-related). For both target groups, vaccine accessibility (process) was least preferred. Statistical significance was reported (or could be determined) in sixteen studies and was most often defined by using $p<0.01$. The average sample size was 1080 . Studies with sample sizes above 500 usually applied multiple thresholds to determine at which point attributes were (not) statistically significant (e.g. p $<0.01, p<0.05$ and $p<0.10)$. Although studies capturing preferences of vaccinees reported statistical significance more often, overall results showed that for both target groups outcome cost-related domains were most frequently significant. The domain other disease related factors (other) was not statistically significant and vaccine accessibility (process) was an equal amount of times significant (at $\mathrm{p}<0.05)$ and insignificant (Additional file 7 ).

\section{Comparison of high- and lower-quality studies}

Eight lower-quality studies focused on vaccinees, fifteen on representatives and three on health advisors (Additional file 5). In line with the approaches used for high-quality studies, studies targeting health advisors were added to the representatives' category and outcomes of Verelst, Kessels, Delva, Beutels \& Willem [79] were split (and grouped under vaccinees as well as representatives). As a result, eighteen studies targeted vaccinees and 27 representatives.

A total of 243 attributes were used, most of which were outcome-related (39.1\%). Compared to high-quality studies, two domains were introduced by lowerquality studies: vaccine content and other. They were both categorized as other. The former referred to substances/components of vaccines such as preservatives and the latter included attributes that could not be grouped under the other seventeen domains (e.g. vaccine testing). All domains that were most often reported and most commonly statistically significant corresponded with high-quality studies, except for disease risk (other). An increased preference for disease risk was observed across both target groups. To illustrate this, disease risk was four times statistically significant in high-quality studies, while it was fifteen times statistically significant in lower-quality studies. Another inconsistency refers to the sample sizes used. Average sample sizes of lower-quality studies were 518 compared to 1080 in high-quality studies. In addition, lower-quality studies tended to use stricter p-value thresholds for sample sizes below 500 , while $p<0.05$ was often used for sample sizes above 500 . With respect to the outcome-related domains, the inclusion of lower-quality studies resulted in another (yet minor) sequence change. Across both target groups, vaccine risk was now most often used and statistically significant, implying that vaccine effectiveness was not most valued anymore. In accordance with high-quality studies, domains related to process and other were least found statistically significant for both target groups. A more detailed comparison of high- and lower-quality studies in enclosed in Additional file 8.

Page $12 / 24$ 


\section{Discussion}

The growing body of SP literature on vaccination highlights the increased interest in the use of choice-based experiments, to elicit preferences for a variety of vaccines and to understand factors influencing vaccine decision-making of different groups of individuals. A total of 42 studies were identified in this review, capturing preferences of three different target groups, covering fourteen vaccines or vaccine programs and with the majority published after 2010 . Given the limited amount of studies assessing preferences of health advisors, this review focused on examining and comparing preferences for vaccine attributes of vaccinees and representatives (including health advisors). The former generally focused on preferences of adults and adolescents, while the latter mainly captured parental preferences for childhood vaccines.

Among the 42 included studies, sixteen studies were of high-quality and could be included in the comparison of vaccine preferences. Irrespective of target group captured, outcome-related attributes, such as vaccine effectiveness, vaccine risk and protection duration, were most frequently reported, followed by attributes covering the monetary cost of vaccines. Outcome- and cost-related attributes were also most commonly statistically significant across all studies, indicating that the same factors are generally preferred across different groups of individuals. Correspondence was also observed for least preferred attributes, since attributes related to a vaccines' access were least valued by both target groups. However, it should be noted that elements of accessibility might already be included in other attributes (e.g. cost, time). In the study of Verelst et al. [79] vaccine accessibility was for instance uni-dimensional and incorporated not only the availability of vaccines, but also its monetary costs. Therefore, it should be interpreted cautiously.

The overall finding is in line with a recent review of Lack et al. [21], which focused on HPV-vaccination and found that vaccinees, parents and providers have the strongest preferences for attributes related to vaccine outcomes. Comparable patterns were also identified among earlier reviews of CAs [20] and DCEs [19] capturing vaccine preferences. Michaels-lgbokwe et al. [19] indicated for instance that attributes related to degree/duration of protection and risk were most often statistically significant across DCEs studying preferences for childhood and adolescent vaccines. In addition, attributes included in DCEs generally addressed features of vaccines, while neglecting service (i.e. process) or contextual aspects (i.e. other). The latter was observed to a lesser extend in this review, as nearly half of the high-quality studies incorporated attributes describing vaccine coverage rates, waiting times, access to vaccines, locations, information provision or social support. However, time and service delivery were not statistically significant in studies among respectively vaccinees and representatives. A more plausible explanation for the underrepresentation would hence be that aspects of a vaccine process are simply less important for vaccinees and representatives in making vaccine decisions. This hypothesis is supported by findings of Guo et al. [45], which outlined that service convenience and quality were less 'dramatic' than vaccine features.

Despite the overall correspondence in preferences of target groups, current findings showed that outcome-related attributes were more often statistically significant in studies targeting vaccinees (esp. vaccine risk), while cost-related attributes were more often statistically significant in studies of representatives. This indicates that the level of evidence for outcomes and costs slightly differed between both target groups. However, outcome and cost parameters were statistically significant in both target groups, indicating no differences in preferences of vaccinees and representatives. Instead differences for cost might be (partly) explained by the definition of this domain. Particularly among studies targeting representatives, cost-related attributes were operationalized differently. They were for instance defined as 'type and value of parental reward (received when full schedule of vaccinations is completed)', 'out-of-pocket cost' and 'payment for one doctor visit'. This might have affected the way in which respondents interpreted attributes and eventually the way in which they valued vaccine scenarios. Studies targeting vaccinees mainly used consistent wording (i.e. 'out-of-pocket cost').

Due to the use of a relatively strict quality-threshold, recommended by the developers of the checklist, 26 lower-quality studies were not considered in the comparison analysis as they were assumed to be susceptible to bias. However, the robustness analysis confirmed findings of the main analysis and only showed a slight increase in preference for attributes covering disease risk. This was observed for both target groups and suggests that epidemiological and affective factors, such as the susceptibility to and severity of diseases, also affect vaccine decisions. Qualitative research on vaccine behaviour and the Health Belief Model confirm this finding and indicate that the valuation of and satisfaction from vaccines is linked to perceptions of vaccines and associated diseases [84-86]. Nonetheless, this discrepancy could also be caused by the conceptual overlap that was identified in the quality assessment. Four lowerquality studies included more than one risk-related attribute, while none high-quality study did so. As a consequence, disease risk was reported more often in lower-quality studies than in high-quality studies. According to Mandeville et al. [31], the occurrence of overlap could distort parameter estimates, as attributes (and effects) are not distinct and do not vary independently of each other. Respondents might for instance experience difficulties in distinguishing between attributes and in interpreting them separately.

When examining characteristics of high- and lower-quality studies, it is observed that all high-quality studies were conducted in HICs and applied MXL/RPL or LCM. In addition, they mainly focused on vaccines against sexually transmitted infections, while lower-quality studies were characterized by a broader range of vaccines, countries and econometric models. High-quality studies were also more likely to pilot test surveys and to express outcomes in WTP or predicted vaccine uptake. The latter is in contrast to Clark et al. [17] who focused on general health preferences and observed a decline in the use of monetary values and probabilities. However, probabilities are particularly useful in vaccination, as herd immunity is an important (but yet hard to achieve) externality which can only be acquired when vaccination coverage passes a certain threshold [87-89]. In addition, adult and traveller vaccines might require (co-)payments, which can be adequately captured in monetary values such as WTP [32]. The trend of using more sophisticated designs and appropriate software, observed in the review of Soekhai [18], is reinforced by current findings. A last remarkable observation refers to the variability in sample sizes and threshold(s) used in studies reporting statistical significance. On average, high-quality studies used larger sample sizes compared to lower-quality studies. High-quality studies with larger sample sizes ( $\geq 500$ ) were also more inclined to use multiple thresholds (i.e. alphas), whereas lower-quality studies used smaller alphas for sample sizes below 500 and $p<0.05$ for sample sizes above 500. Particularly the latter is contrast with previous research, which indicates that larger sample sizes are required when lowering alpha and vice versa $[90,91]$. 
With respect to the quality assessment, this review reported an average score of 9.3, which was almost one point higher than reported by Michaels-lgbokwe et al. in 2017 (score: 8.4) [19]. This may suggest that choice-based experiments have improved elements of design in the last couple of years. However, no improvement was observed in our quality scores per period. Furthermore, the quality assessment indicated that industry-funded studies scored remarkably lower than non-industry funded studies. This addresses the need to get insight into industry sponsorship and used methodology. As observed by previous reviews using the 13-criteria checklist [19,31], a variety of scores was administered and none reached the maximum score of 13 . All included studies failed at least one criterion. Weaknesses were particularly observed on elements of choice task design, experimental design and conduct. This underlines once again the technical requirements for all four stages and highlights the need to improve scientific rigour across choice-experiments in health.

\section{Strengths and weaknesses}

A strength of this study is the use of a formal quality assessment tool [31] to critically appraise the methodological quality and internal validity of included studies. Despite the evidence indicating that quality scores not necessarily reflect a study's validity, the tool has demonstrated its usability in previous reviews in health $[19,31,92]$. A quality threshold of $75 \%$ was used, as it was assumed that only studies who satisfied at least 10 out of 13 criteria were able to exclude most threats to validity occurring along the four stages of individual choice experiments. This promoted the internal validity of this review, since conclusions regarding drivers of vaccine decisions were based on attributes identified in high-quality studies only [31, 36, 93]. In addition, robustness of current findings was tested and confirmed in the comparison of high- and lower-quality studies. Based on this analysis, it could be ascertained that findings were largely not affected by exclusion of lower-quality studies [37]. The comprehensiveness of the search is also a strength. As indicated in the method section, the primary search was updated and related reviews were screened. Only two additional studies were identified, confirming the accuracy of key words used and suggesting that the primary was all-encompassing [27]. However, data was extracted from published literature and relied on what was reported in articles and available supplementary material. Like in any review, reporting and publication bias could hence not be eliminated [93, 94]. A last strength refers to eligibility criteria. In contrast to previous research, no in- or exclusion criteria were formulated based on vaccine topic or site examined. Included studies hence covered a variety of vaccines/programs, populations and settings. This heterogeneity promoted the representativeness and improved generalisability (external validity) of current findings [37]. Due to the limited research on preferences in low-resource countries and of healthcare professionals, both were still underrepresented which may hamper generalisability of results to these particular populations and settings.

Beside strengths, some limitations could also be identified. This review was limited to choice-based experiments and excluded studies without a component of choice. Scaling approaches in which respondents were asked to rate or rank vaccine scenarios (e.g. best-worst scaling), were for instance not taken into account. Eleven studies were excluded based on this criterion (eight primary search, three snowballing), most of which focused on vaccines against HIV [95102]. In addition, key steps of this review were performed by a single researcher. This may have induced reporting bias as data was not extracted and interpreted by two researchers independently $[36,93,94]$. To minimize the occurrence of inconsistencies/mistakes, all steps were closely monitored and checked by a second researcher and ambiguities were discussed and agreed upon. Due to the heterogeneity of studies included, a variety of attributes were used. To reduce the number of attributes, the commonly used classification of outcome, cost and process was used [21, 103-105]. However, multiple attributes could not be classified properly, and a fourth category, other, needed to be added. This category included many different attributes (and domains), which ranged from disease-specific to societal or contextual factors. This variety hampered appropriate naming and interpretation of the category as a whole. Besides, the decision was made to include health advisors into the representatives' group, because both referred to individuals that make vaccine decisions for others and there were only four studies focusing on health advisors. Particularly given the latter, it was considered inappropriate to create a separate group. In addition, analyses revealed that no new domains were introduced by the studies of health advisors, which suggests that the inclusion of both had no influence on the findings about representatives. The last, yet most important limitation refers to the approach to identify factors driving vaccine decisions. Due to the range of vaccines, attributes, choice tasks, populations and outcome measures within the included studies, it was not possible to pool results into a combined effect by means of a meta-analysis [106]. Due to reproducibility problems, it was also not feasible to assess the relative importance per attribute and thereby to indicate whether an attribute was more important than another. Instead, drivers were based on frequency of reporting and statistical significance of domains. Although both measures give an indication about the importance of attributes, the adequacy is discussible. Statistical significance is not only contingent upon the set of attributes used, but also on the way in which it is defined [36, 90, 91]. An attribute could for instance be considered statistically significant in one study (at $p<0.10)$, while it is not in another that used a smaller alpha (e.g. $p<0.01)$. The frequency of reporting domains was also skewed by studies including more than one attribute of the same domain. This distortion as well as the variability in significance levels hampered interpretability and may have induced bias on outcome level. Nonetheless, this was tried to minimize by accounting for significance levels (alphas) used and the amount of studies reporting certain domains.

\section{Implications for research and policy Implications for research}

Despite the importance of ensuring the accuracy of vaccine preferences, the quality assessment showed that the choice task, experimental design and elements of conduct received less attention compared to analysis. Studies conducted in LMICs particularly reported inappropriate experimental designs, showed conceptual overlap across attributes and failed to pilot test the survey among a small sample of the target population. In 2017, Michaels-lgbokwe et al. [19] observed similar methodological patterns and already highlighted to need to improve the design and context of DCEs. Although fourteen studies published afterwards improved pilot testing, similar scores were reported on the experimental design and sufficiency of response rate. In addition, scores on conceptual overlap even decreased. This indicates that choice experiments in vaccination have not yet structurally improved their designs and conduct since then. The time lag between the conduct of a study and publication of results could play a role, as high-quality studies were on average published three years after its conduct. Improvements in choice design and conduct are notwithstanding crucial to ensure reliable estimates of vaccine preferences. As recommended by Soekhai et al. [18] this might be facilitated by formulation of guidelines to report choice experiments. 
Furthermore, this review intended to study three distinct target groups. Due to the limited amount of studies on preferences of health professionals, no conclusions could be drawn for this decision-making role. As literature $[9,107,108]$ showed that decision strategies particularly differ for medical professionals and vaccinees, future research could focus on preferences of healthcare professionals to assess whether similar vaccine attributes are preferred by them as well. This could potentially be done by broadening the approaches used to measure SP (e.g. add contingent valuation). Given the scope of this review, included studies were grouped based on the decision-maker targeted and not on the type of vaccine. Although Lack et al. [21] focused on HPV vaccination, limited studies were available for other vaccines/vaccination programs. Therefore, it was not possible to use a classification based on vaccine type. A classification based on broader target groups would still be possible and future research could focus for instance on childhood vaccines, adult vaccines and/or traveller vaccines. However, it should be noted that our classification already encompassed some of these groups, as vaccinees often involved decisions for adolescent or adult vaccines and representatives commonly concerned parental decisions (for childhood vaccines). Additional research could also focus on target groups other than those distinguished in this review (e.g. policy makers, based on gender) or on vaccine preferences in low-resource settings. A combination of both would also be interesting as qualitative research $[109,110]$ indicated that national decision-makers in LMICs particularly preferred simplified delivery mechanisms, thermostability and an extended shelf-life. In light of the current corona pandemic and ongoing search towards an appropriate vaccine, it would also be worthwhile to assess preferences for (future) vaccines against epidemic infections, such as COVID-19 and SARS, and to determine whether vaccine preferences differ based on epidemic severity.

\section{Implications for policy}

In contrast to what is suggested in previous qualitative studies $[9,11,12]$, this review demonstrates that vaccine preferences show similar patterns for vaccinees and representatives. This means that broadly the same strategies could be adopted to promote and optimize vaccination behaviour. Vaccine strategies should focus on highlighting outcome-related vaccine attributes. Proper and understandable information should thus be provided about the effectiveness of vaccines, duration of effectiveness and risks associated with vaccine administration, dosing and handling. Insight into the latter is particularly important for vaccinees. Another key driver in vaccine decisions is the cost of vaccines. Therefore, effective pricing strategies should be applied (if applicable) when introducing or continuing the use of vaccines. Particularly for vaccine decisions that involve representatives (e.g. childhood vaccines), the element of cost is important. Although this study primarily focused on attributes of vaccines and vaccine programs, the robustness analysis indicated that disease risk is important for vaccinees and representatives as well. Therefore, information strategies should not only cover vaccine-related aspects, but should also inform target groups about the severity and probability of diseases. With respect to the design of vaccine programs, service or process-related factors such as location and waiting time were less important compared to vaccine scheduling and number of doses or visits. Across included studies, individuals value a reduced number of doses/visits when deciding for themselves and others, which implies that vaccine programs should try to minimize the amount of dosages as much as possible. As outlined in previous research [111,112], combination vaccines offer the potential to reduce the amount of injections, visits and associated costs. Although most childhood vaccines already involve combination vaccines, adolescent vaccines such as the HPV vaccine still consist of multiple injections. Despite the clinical superiority of two- and three-dose HPV vaccines, Pinto, Dillner, Beddows \& Unger [113] observed that there is yet some evidence indicating that one dose may provide similar protection.

\section{Conclusion}

Where previous literature reviews were restricted to specific target groups, type of vaccines or formats of choice experiments, this review was the first to examine vaccine preferences of different target groups across vaccines. A clear and comprehensive overview of current SP literature was provided, which not only gave insight into the four main drivers of vaccine decision-making and the correspondence between vaccinees and representatives, but also indicated room for improvement across three of the four stages of choice experiments. Future research into vaccine preferences of target groups other than that were currently studied (especially health advisors) and/or among groups in low-resource settings would give insight into the generalizability of current findings.

\section{Abbreviations}

ADCE: Adaptive Discrete Choice Experiment; CA: Conjoint Analysis; CLM: Conditional Logit Model; DCE: Discrete Choice Experiment; HIC: High-Income-Country; ISPOR: International Society for Pharmacoeconomics and Outcomes Research; LCM: Latent Class Model; LMIC: Low-Middle-Income-Country; MNL: Multinomial logit model; MXL: Mixed Logit Model; RP: Revealed Preferences; RPL: Random Parameter Logit Model; SP: Stated Preferences; UMIC: UpperMiddle-Income Country; WTP: Willingness-To-Pay.

\section{Declarations}

\section{Acknowledgements}

We would like to thank the reviewers for their time, effort and feedback on our manuscript.

\section{Authors' contributions}

IvdP, MD and MH conceived this study and were involved in the conception and design of the study. MD conducted the data collection, analysis and interpretation and drafted the manuscript. IvdP supported the collection and interpretation of the data and performed a check for quality control. MH critically reviewed the manuscript. All authors approved the final manuscript.

\section{Funding}

No funding was received for the conduct of this study. 
Availability of data and materials

The datasets used and/or analyzed during the current study are available from the corresponding author on reasonable request.

\section{Ethics approval and consent to participate}

Not applicable.

\section{Consent for publication}

Not applicable.

\section{Competing interests}

The authors declare that they have no competing interests.

\section{References}

1. European centre for disease prevention and control. Individual decision-making and childhood vaccination, meeting report 24 May 2013 . Stockholm: ECDC; 2013.

2. Dubé E, Laberge C, Guay M, Bramadat P, Roy R, Bettinger J. Vaccine hesitancy, an overview. Human Vaccin Immunother. 2013;9(8):1763-73.

3. Hensher D, Rose J, Greene W. Applied choice analysis. 2nd ed. Cambridge: Cambridge University Press; 2015.

4. Brown KF et al. Factors underlying parental decisions about combination childhood vaccinations including MMR: a systematic review. Vaccine. 2010;28(26):4235-48.

5. Harmsen, IA, Ruiter RAC, Paulussen TGW, Mollema L, Kok G, de Melker HE. Factors that influence vaccination decision-making by parents who visit an anthroposophical child welfare center: a focus group study. Adv Prev Med. 2012; 2012:1-7.

6. Chung Y, Schamel J, Fisher A, Frew PM. Influences on immunization decision-making among US parents of young children. Matern Child Health J. 2017;21(12):2178-87.

7. Wachob DA, Boldy A. Social media's influence on parents' decision-making process of child vaccinations. Epidemiol Biostat Public Health. 2019;16(1):15.

8. Sisson H, Wilkinson Y. An integrative review of the influences on decision-making of young people about human papillomavirus vaccine. J Sch Nurs. 2019;35(1):39-50.

9. Zikmund-Fisher, BJ. Sarr B, Fagerlin A, Ubel PA. A matter of perspective: choosing for others differs from choosing for yourself in making treatment decisions. J Gener Int Med. 2006;21(6):618-22.

10. Ministry of Health. Immunisation handbook 2017. 2nd ed. Wellington: Ministry of Health; 2018.

11. Goldstein WM, Weber EU. Content and discontent: indications and implications of domain specificity in preferential decision making. Psychol Learn Motiv. 1995;32:83-136.

12. Thompson AGH. The meaning of patient involvement and participation in health care consultations: a taxonomy. Soc Sci Med. 2007;64(6):1297-310.

13. World Health Organization. Immunization coverage. 2019. https://www.who.int/en/news-room/fact-sheets/detail/immunization-coverage. Accessed 8 June 2019.

14. Strategic Advisory Group of Experts on immunization. 2018 assessment report of the global vaccine action plan. Geneva: WHO; 2018.

15. Louviere JJ, Hensher DA, Swait JD. Stated choice methods: analysis and applications. Cambridge: Cambridge University Press; 2000.

16. Carlsson F. Non-market valuation: stated preference methods. In: Lusk JL, Roosen J, Shogren JF, editors. The Oxford handbook of the economics of food consumption and policy. Oxford: Oxford University Press; 2011. p. 181-215.

17. Clark MD, Determann D, Petrou S, Moro D, de Bekker-Grob, EW. Discrete choice experiments in health economics: a review of the literature. Pharmacoeconomics. 2014;32(9):883-902.

18. Soekhai V, de Bekker-Grob EW, Ellis AR, Vass CM. Discrete choice experiments in health economics: past, present and future. Pharmacoeconomics. 2019;37(2):201-26.

19. Mickaels-lgbowke C, MacDonald S, Currie GR. Individual preferences for child and adolescent vaccine attributes: a systematic review of the stated preference literature. Patient. 2017;10(6):687-700.

20. Poulos C. A review of conjoint-analysis studies of vaccine preferences. In: ISPOR 21st annual international meeting; 2016 May 21-25; Washington DC, United States. Research Triangle Park: RTI Health Solutions; 2016.

21. Lack A, Hiligsmann M, Bloem P, Tünneßen M, Hutubessy R. Parent, provider and vaccinee preferences for HPV vaccination: a systematic review of discrete choice experiments. Vaccine. 2020;38(46):7226-38.

22. Institute of Medicine. Informed vaccine decision making. In: Institute of Medicine. Priorities for the National Vaccine Plan. Washington (DC): National Academies Press; 2010. p. 79-96.

23. Dubé E, Gagnon D, MacDonald NE, SAGE working group on vaccine hesitancy. Strategies intended to address vaccine hesitancy: review of published reviews. Vaccine. 2015;33(34):4191-203. 
24. Sadaf A, Richards JL, Glanz J, Salmon DA, Omer SB. A systematic review of interventions for reducing parental vaccine refusal and vaccine hesitancy. Vaccine. 2013;31(40):4293-304.

25. Odone A, Fara GM, Giammaco G, Blangiardi F, Signorelli C. The future of immunization policies in Italy and the European Union: the declaration of Erice. Human Vaccin Immunother. 2015;11(5):1268-71.

26. EC. Council Recommendation of 7 December 2018 on strengthened cooperation against vaccine-preventable diseases. 0J. 2018;466:1-17.

27. Wohlin C. Guidelines for snowballing in systematic literature studies and a replication in software engineering. In: EASE '14, Proceedings of the 18th International Conference on Evaluation and Assessment in Software Engineering; 2014 May 13-14; London. New York: Association for Computing Machinery; 2014.

28. De Bekker-Grob EW, Ryan M, Gerard K. Discrete choice experiments in health economics: a review of the literature. Health Econ 2012;21(2):145-72.

29. Ryan M, Gerard K. Using discrete choice experiments to value health care programmes: current practice and future research reflections. Appl Heal Econ Heal Policy 2003;2(1):55-64.

30. Moher D, Liberati A, Tetzlaff J, Altman DG. Preferred reporting items for systematic reviews and meta-analyses: The PRISMA statement. PLoS Med. 2008;6(7):e1000097.

31. Mandeville KL, Lagarde M, Hanson K. The use of discrete choice experiments to inform health workforce policy: a systematic review. BMC Health Serv Res. 2014;14(1):367.

32. Lancsar E, Louviere J: Conducting discrete choice experiments to inform healthcare decision making: a user's guide. Pharm Econ. 2008;26(8):661-77.

33. Bridges JF, Hauber AB, Marshall D, et al. Conjoint analysis applications in health: a checklist: a report of the ISPOR Good Research Practices for Conjoint Analysis Task Force. Value Health. 2011;14(4):403-13.

34. Higgins JPT, Green S, editors: Cochrane handbook for systematic reviews of interventions version 5.1.0 (updated March 2011). The Cochrane Collaboration; 2011. . Accessed 15 June 2020.

35. Jüni P, Witschi A, Bloch R, Egger M. The hazards of scoring the quality of clinical trials for meta-analysis. JAMA. 1999;282(11):1054-60.

36. Munro BH. Statistical methods for health care research. 5th ed. Philadelphia: Wolters Kluwer Health/Lippincott Williams \& Wilkins; 2005.

37. Holly C, Salmond SW, Saimbert MK. Comprehensive systematic review for advanced nursing practice. New York: Springer Publishing Company; 2012.

38. Polit DF, Beck CT. Nursing research. Generating and assessing evidence for nursing practice. 10th ed. Philadelphia: Wolters Kluwer Health/Lippincott Williams \& Wilkins; 2017.

39. Centrale Commissie Mensgebonden Onderzoek. Uw onderzoek: WMO-plichtig of niet?. Den Haag: CCMO; n.d. https://www.ccmo.nl/onderzoekers/wet-enregelgeving-voor-medisch-wetenschappelijk-onderzoek/uw-onderzoek-wmo-plichtig-of-niet Accessed 20 Jan 2020.

40. Ledent E, Gabutti G, de Bekker-Grob EW, Alcázar Zambrano JL, Campins Martí M, Del Hierro Gurruchaga MT, et al. Attributes influencing parental decisionmaking to receive the Tdap vaccine to reduce the risk of pertussis transmission to their newborn - outcome of a cross-sectional conjoint experiment in Spain and Italy. Hum Vaccin Immunother. 2019;15(5):1080-91.

41. Cunningham CE, Ken Deal, Chen Y. Adaptive choice-based conjoint analysis. A new patient-centered approach to the assessment of health service preferences. Patient. 2010;3(4):257-73.

42. Marshall HS, Chen G, Clark M, Ratcliffe J. Adolescent, parent and societal preferences and willingness to pay for meningococcal B vaccine: A Discrete Choice Experiment. Vaccine. 2016;34(5):671-7.

43. Poulos C, Standaert B, Sloesen B, Stryjewska I, Janitsary A, Hauber B. Preferences for vaccines against children's diarrheal illness among mothers in Poland and Hungary. Vaccine. 2018;36(40):6022-9.

44. Bishai D, Brice R, Girod I, Saleh A, Ehreth J. Conjoint analysis of French and German parents' willingness to pay for meningococcal vaccine. Pharmacoeconomics. 2007;25(2):143-54.

45. Reed Johnson F et al. Constructing experimental designs for discrete-choice experiments: report of the ISPOR conjoint analysis experimental design good research practices task force. Value Health. 2013;16(1):3-13.

46. Guo N, Zhang G, Zhu D, Wang J, Shi L. The effects of convenience and quality on the demand for vaccination: Results from a discrete choice experiment. Vaccine. 2017;35(21):2848-54.

47. Adams J, Bateman B, Becker F, Cresswell T, Flynn D, McNaughton R, et al. Effectiveness and acceptability of parental financial incentives and quasimandatory schemes for increasing uptake of vaccinations in preschool children: systematic review, qualitative study and discrete choice experiment. Health Technol Assess. 2015;19(94):1-176.

48. Veldwijk J, Lambooij MS, Bruijning-Verhagen PCJ, Smit HA, de Wit GA. Parental preferences for rotavirus vaccination in young children: A discrete choice experiment. Vaccine. 2014;32(47):6277-83.

49. Brown DS, Poulos C, Reed Johnson F, Chamiec-Case L, Messonnier ML. Adolescent girls' preferences for HPV vaccines: a discrete choice experiment. Adv Health Econ Health Serv Res. 2014;24;93-121.

50. Brown DS, Reed Johnson F, Poulos C, Messonnier ML. Mothers' preferences and willingness to pay for vaccinating daughters against human papillomavirus. Vaccine. 2010;28(7):1702-8.

51. Hofman R, de Bekker-Grob EW, Richardus JH, de Koning HJ, van Ballegooijen M, Korfage IJ. Have preferences of girls changed almost 3 years after the much debated start of the HPV vaccination program in the Netherlands? A discrete choice experiment. PloS One. 2014;9(8):e104772.

52. Lloyd AJ et al. What are the preferences of health care professionals in Germany regarding fully liquid, ready-to-use hexavalent pediatric vaccine versus hexavalent pediatric vaccine that needs reconstitution? Patient Prefer Adherence 2015;9:1517-24.

Page $17 / 24$ 
53. de Bekker-Grob EW, Jorien Veldwijk J, Jonker M, Donkers B, Huisman J, Buis S, et al. The impact of vaccination and patient characteristics on influenza vaccination uptake of elderly people: A discrete choice experiment. Vaccine. 2018;36(11):1467-76.

54. Poulos C, Yang JC, Levin C, Van Minh H, Giang KB, Nguyen D. Mothers' preferences and willingness to pay for HPV vaccines in Vinh Long Province, Vietnam. Soc Sci Med. 2011;73(2):226-34.

55. Liao Q, Ng TWY, Cowling BJ. What influenza vaccination programmes are preferred by healthcare personnel? A discrete choice experiment. Vaccine 2020;38(29):4557-62.

56. Hall J, Kenny P, King M, Louviere J, Viney R, Yeoh A. Using stated preference discrete choice modelling to evaluate the introduction of varicella vaccination. Health Econ. 2002;11(5):457-65.

57. Orme B. Sample size issues for conjoint analysis. In: Orme B, editor. Getting started with conjoint analysis: strategies for product design and pricing research. 4rd ed. Madison (WI): Research Publishers LLC; 2010. p. 57-65.

58. de Bekker-Grob EW. Discrete choice experiments in healthcare. Theory and applications. Rotterdam: Erasmus University; 2009.

59. Ngorsuraches S, Nawanukool K, Petcharamanee K, Poopantrakool U. Parents' preferences and willingness-to-pay for human papilloma virus vaccines in Thailand. J Pharm Policy Pract. 2015;8(1):20.

60. Arbiol J, Yabe M, Nomura H, Borja M, Gloriani N, Yoshida S. Using discrete choice modeling to evaluate the preferences and willingness to pay for leptospirosis vaccine. Hum Vaccin Immunother. 2015;11(4):1046-56.

61. de Bekker-Grob EW, Hofman R, Donkers B, van Ballegooijen M, Helmerhorst TJM, Raat H, et al. Girls' preferences for HPV vaccination: a discrete choice experiment. Vaccine. 2010;28(41):6692-7.

62. Determann D, Korfage IJ, Fagerlin A, Steyerberg EW, Bliemer MC, Voeten HA, et al. Public preferences for vaccination programmes during pandemics caused by pathogens transmitted through respiratory droplets - a discrete choice experiment in four European countries, 2013. Euro Surveill. 2016;21(22):pii = 30247 .

63. Determann D, Korfage IJ, Lambooij MS, Bliemer M, Richardus JH, Steyerberg EW, et al. Acceptance of vaccinations in pandemic outbreaks: a discrete choice experiment. PLoS One. 2014;9(7):e102505.

64. Eilers R, de Melker HE, Veldwijk J, Krabbe PFM. Vaccine preferences and acceptance of older adults. Vaccine. 2017;35(21):2823-30.

65. Flood EM, Ryan KJ, Rousculp MD, Beusterien KM, Block SL, Hall MC, et al. A survey of children's preferences for influenza vaccine attributes. Vaccine. 2011;29(26):4334-40.

66. Flood EM, Ryan KJ, Rousculp MD, Beusterien KM, Divino VM, Block SL, MD, et al. Parent preferences for pediatric influenza vaccine attributes. Clin Pediatr. 2011;50(4):338-47.

67. Gidengil C, Lieu TA, Payne K, Rusinak D, Messonnier M, Prosser LA. Parental and societal values for the risks and benefits of childhood combination vaccines. Vaccine. 2012;30(23):3445-52.

68. Hofman R, de Bekker-Grob EW, Raat H, Helmerhorst TJM, van Ballegooijen M, Korfage IJ. Parents' preferences for vaccinating daughters against human papillomavirus in the Netherlands: a discrete choice experiment. BMC Public Health. 2014;14:454.

69. Huang Z, Wagner AL, Lin M, Sun X, Zikmund-Fisher BJ, Boulton ML, et al. Preferences for vaccination program attributes among parents of young infants in Shanghai, China. Hum Vaccin Immunother. 2020:1-6.

70. Lambooij MS, Harmsen IA, Veldwijk J, de Melker H, Mollema L, van Weert YWM. Consistency between stated and revealed preferences: a discrete choice experiment and a behavioural experiment on vaccination behaviour compared. BMC Med Res Methodol. 2015;15:19.

71. Liao Q, Lam WWT, Wong CKH, Lam C, Chen J, Fielding R. The relative effects of determinants on Chinese adults' decision for influenza vaccination choice: What is the effect of priming? Vaccine. 2019;37(30):4124-32.

72. Oteng B, Marra F, Lynd LD, Ogilvie G, Patrick D, Marra CA. Evaluating societal preferences for human papillomavirus vaccine and cervical smear test screening programme. Sex Transm Infect. 2011;87(1):52-7.

73. Pereira CCA, Mulligan M, Bridges JFP, Bishai D. Determinants of influenza vaccine purchasing decision in the US: a conjoint analysis. Vaccine. 2011;29(7):1443-7.

74. Poulos C, Curran D, Anastassopoulou A, de Moerlooze L. German travelers' preferences for travel vaccines assessed by a discrete choice experiment. Vaccine. 2018;36(7):969-78.

75. Poulos C, Reed Johnson F, Krishnarajah G, Anonychuk A, Misurski D. Pediatricians' preferences for infant meningococcal vaccination. Value Health. 2015;18(1):67-77.

76. Sadique MZ, Devlin N, Edmunds WJ, Parkin D. The effect of perceived risks on the demand for vaccination: results from a discrete choice experiment. PLoS One. 2013;8(2):e54149.

77. Sapède C, Girod I. Willingness of adults in Europe to pay for a new vaccine: the application of discrete choice-based conjoint analysis. Int $\mathrm{J}$ Mark Res 2002;44(4):463-76.

78. Seanehia J, Treibich C, Holmberg C, Müller-Nordhorn J, Casin V, Raude J. Quantifying population preferences around vaccination against severe but rare diseases: a conjoint analysis among French university students, 2016. Vaccine. 2017;35(20):2676-84.

79. Shono A, Kondo M. Mothers' preferences regarding new combination vaccines for their children in Japan, 2014. Hum Vaccin Immunother. 2017;13(4):766-71.

80. Shono A, Kondo M. Parents' preferences for seasonal influenza vaccine for their children in Japan. Vaccine. 2014;32(39):5071-6. 
81. Sun X, Wagner AL, Ji J, Huang Z, Zikmund-Fisher BJ, Boulton ML. A conjoint analysis of stated vaccine preferences in Shanghai, China. Vaccine. 2020;38(6):1520-5.

82. Verelst F, Kessels R, Delva W, Beutels P, Willem L. Drivers of vaccine decision-making in South Africa: a discrete choice experiment. Vaccine. 2019;37(15):2079-89.

83. Verelst F, Willem L, Kessels R, Beutels P. Individual decisions to vaccinate one's child or oneself: a discrete choice experiment rejecting free-riding motives. Soc Sci Med. 2018;207:106-16.

84. Wang B, Chen G, Ratcliffe J, Afzali HHA, Giles L, Marshall H. Adolescent values for immunisation programs in Australia: a discrete choice experiment. PLoS One. 2017;12(7): e0181073.

85. Wong CKH, Man KKC, Ip P, Kwan M, McGhee SM. Mothers' preferences and willingness to pay for human papillomavirus vaccination for their daughters: a discrete choice experiment in Hong Kong. Value Health. 2018;21(5):622-9.

86. Lancsar E, Louviere J, Flynn T. Several methods to investigate relative attribute impact in stated preference experiments. Soc Sci Med. 2007;64(8):173853.

87. Schmid P, Rauber D, Betsch C, Lidolt G, Denker ML. Barriers of influenza vaccination intention and behaviour - a systematic review of influenza vaccine hesitancy, 2005-2016. PLoS One. 2017;12(1):e0170550.

88. Chapman GB, Coups EJ. Emotions and preventive health behaviour: worry, regret and influenza vaccination. Health Psychol. 2006;25(1)82-90.

89. Bond L, Noland T. Making sense of perceptions of risk of diseases and vaccinations: a qualitative study combining models of beliefs, decision-making and risk perception. BMC Public Health. 2011;11:943.

90. Fine P, Eames K, Heymann DL. “Herd immunity”: a rough guide. Clin Infect Dis. 2011;52(7):911-6.

91. European Council. The state of health of vaccination in the EU. Rome: EC; 2014.

92. Strategic Advisory Group of Experts on immunization. 2018 assessment report of the global vaccine action plan. Geneva: WHO; 2018.

93. de Bekker-Grob EW, Donkers B, Jonker MF, Stolk EA. Sample size requirements for discrete-choice experiments in healthcare: a practical guide. Patient. 2015;8(5):373-84.

94. Lakens D, et al. Justify your alpha. Nat Hum Beh. 2018;2(3):168-71.

95. Trapero-Bertran M, Rodrígues-Martín B, López-Bastida J. What attributes should be included in a discrete choice experiment related to health technologies? A systematic literature review. PloS One. 2019;14(7):e0219905.

96. Boutron I, Page MJ, Higgins JPT, Altman DG, Lundh A, Hróbjartsson A. Chapter 7: Considering bias and conflicts of interest among the included studies. In: Higgins JPT, Thomas J, Chandler J, Cumpston M, Li T, Page MJ, Welch VA, editors. Cochrane handbook for systematic reviews of interventions version 6.0 (updated July 2019). Cochrane; 2019. . Accessed 26 June 2020.

97. Drucker AM, Fleming P, Chan A. Research techniques made simple: assessing risk of bias in systematic reviews. J Invest Dermatol. 2016;136(11):109-14.

98. Bair RM, Mays RM, Sturm LA, Perkins SM, Juliar BE, Zimet GD. Acceptability to Latino parents of sexually transmitted infection vaccination. Ambul Pediatr. 2008;8(2)98-103.

99. Cameron MP, Newman PA, Roungprakhon S, Scarpa R. The marginal willingness-to-pay for attributes of a hypothetical HIV vaccine. Vaccine. 2013;31(36):3712-7.

100. Lee SJ, Brooks RA, Newman PA, Seiden D, Sangthong R, Duan N. HIV vaccine acceptability among immigrant Thai residents in Los Angeles: a mixedmethod approach. AIDS care. 2008;20(10):1161-8.

101. Lee SJ, Newman PA, Comulada WS, Cunningham WE, Duan N. Use of conjoint analysis to assess HIV vaccine acceptability: feasibility of an innovation in the assessment of consumer health-care preferences. Int J STD AIDS. 2012;23(4):235-41.

102. Newman et al. HIV vaccine acceptability among communities at risk: the impact of vaccine characteristics. Vaccine. 2006;24(12):2094-101.

103. Stockwell MS, Rosenthal SL, Sturm LA, Mays RM, Bair RM, Zimet GD. The effects of vaccine characteristics on adult women's attitudes about vaccination: a conjoint analysis study. Vaccine. 2011;29(17):4507-11.

104. Weaver J, Newman PA, Williams CC, Notisha Massaquoi N, Brown M. "Sisters, mothers, daughters and aunties": HIV vaccine acceptability among African, Caribbean and other black women in Toronto. Can J Public Health. 2013:104(05):e413-7.

105. Zimet GD, Mays RM, Sturm LA, Ravert AA, Perkins SM, Juliar BE. Parental attitudes about sexually transmitted infection vaccination for their adolescent children. Arch Pediatr Adolesc Med. 2005;159(2):132-7.

106. Bien DR, Danner M, Vennedey V, Civello D, Evers SM, Hiligsmann M. Patients' preferences for outcome, process and cost attributes in cancer treatment: a systematic review of discrete choice experiments. Patient 2017;10(5):553-65.

107. Sain N, Willems D, Charokopou M \& Hiligsmann M. The importance of understanding patient and physician preferences for psoriasis treatment characteristics: a systematic review of discrete- choice experiments. Curr Med Res Opin 2020;36(8):1257-75.

108. Schaarschmidt M-L et al. Patient preferences for psoriasis treatments: process characteristics can outweigh outcome attributes. Arch Dermatol 2011;147(11):1285-94.

109. Littell J, Corcoran J, Pillai V. Systematic reviews and meta-analysis. New York: Oxford University Press; 2008.

110. Wroe AL, Turner N, Salkovskis PM. Understanding and predicting parental decisions about early childhood immunizations. Health Psychol. 2004;23(1):33-41.

111. Wroe AL, Bhan A, Salkovskis P, Bedford, H. Feeling bad about immunising our children. Vaccine. 2005; 23(12):1428-33. 
112. Kristensen DD, Bartholomew K, Villadiego S, Lorenson K. What vaccine product attributes do immunization program stakeholders value? Results from interviews in six low- and middle-income countries. Vaccine. 2016;34(50):6236-42.

113. Neuzil KM. Data and product needs for influenza immunization programs in low- and middle-income countries: rationale and main conclusions of the WHO preferred product characteristics for next-generation influenza vaccines. Vaccine. 2017;35(43):5734-7.

114. Visser A, Hoosen A. Combination vaccines in the South African setting. Vaccine. 2012;30 Suppl 3:C38-44.

115. Venkatesan MM, van de Verg LL. Combination vaccines against diarrheal diseases. Hum Vaccin Immunother. 2015;11(6):1434-48.

116. Pinto LA, Dillner J, Beddows S, Unger ER. Immunogenicity of HPV prophylactic vaccines: serology assays and their use in HPV vaccine evaluation and development. Vaccine. 2018;36(32):4792-9.

\section{Supplementary Information}

Additional file 1: Overview of search strategy. A table describing the search applied in each of the databases.

Additional file 2: Overview of study characteristics. A complete overview of the characteristics of all studies included in this review.

Additional file 3: Overview of attributes included in each domain/category. A table giving insight into the way attributes were grouped under domains and categories.

Additional file 4: Quality assessment. A detailed description of the outcomes of the quality assessment performed.

Additional file 5: Overview of vaccine attributes per study. A detailed overview of the vaccine attributes and domains used in each of the studies (incl. statistical significance)

Additional file 6: Importance rankings vaccine attributes. Tables outlining the frequency in which domains were reported among high- and lower-quality studies.

Additional file 7: Relative statistical significance (overall preferences). Tables giving insight into the amount of times domains were reported statistically significant in all studies (overall preferences).

Additional file 8: Comparison of high- and lower-quality studies. A more detailed description of findings of the robustness analysis.

\section{Figures}




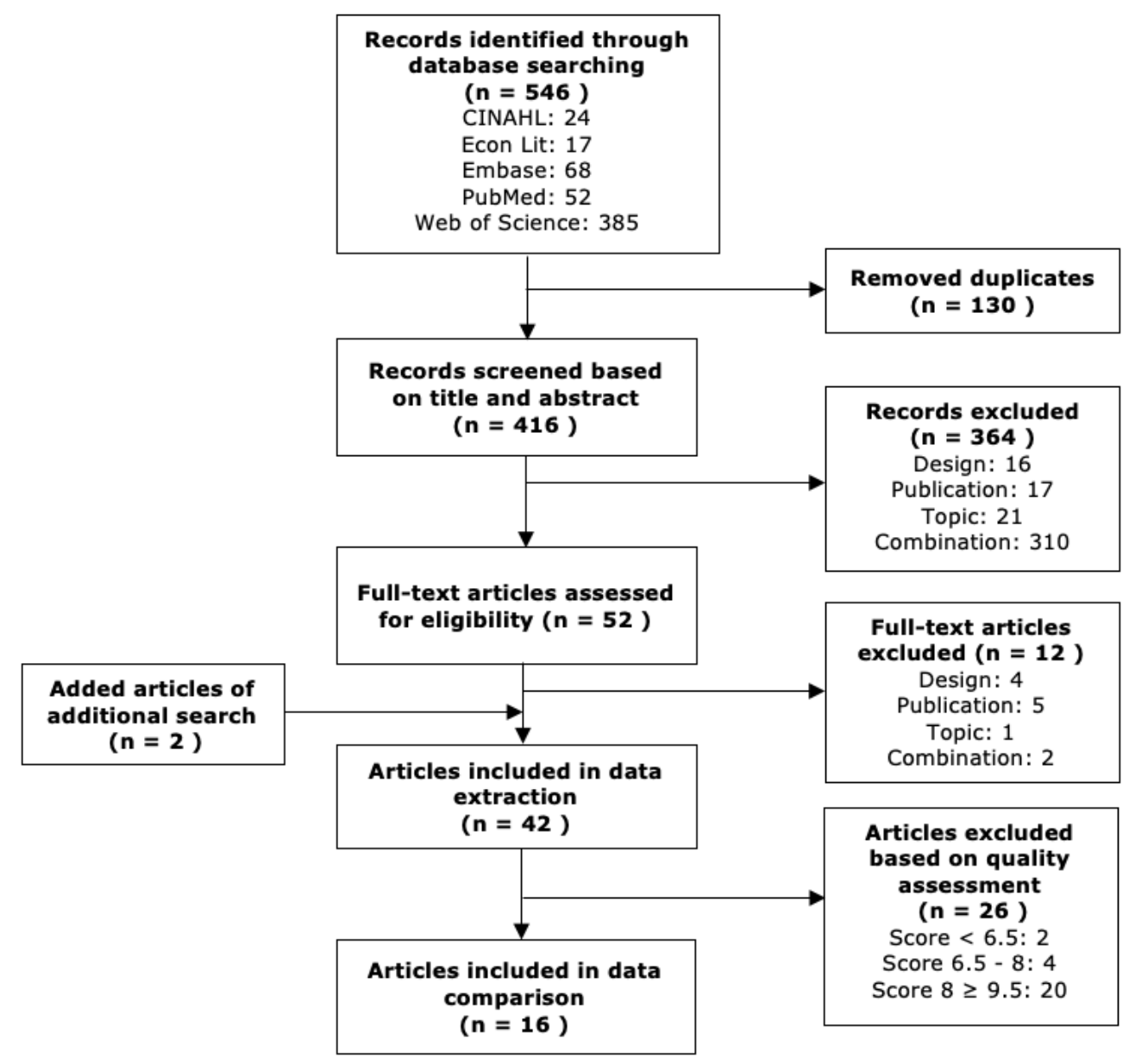

Figure 1

PRISMA flow diagram of choice-based experiments capturing vaccine preferences 


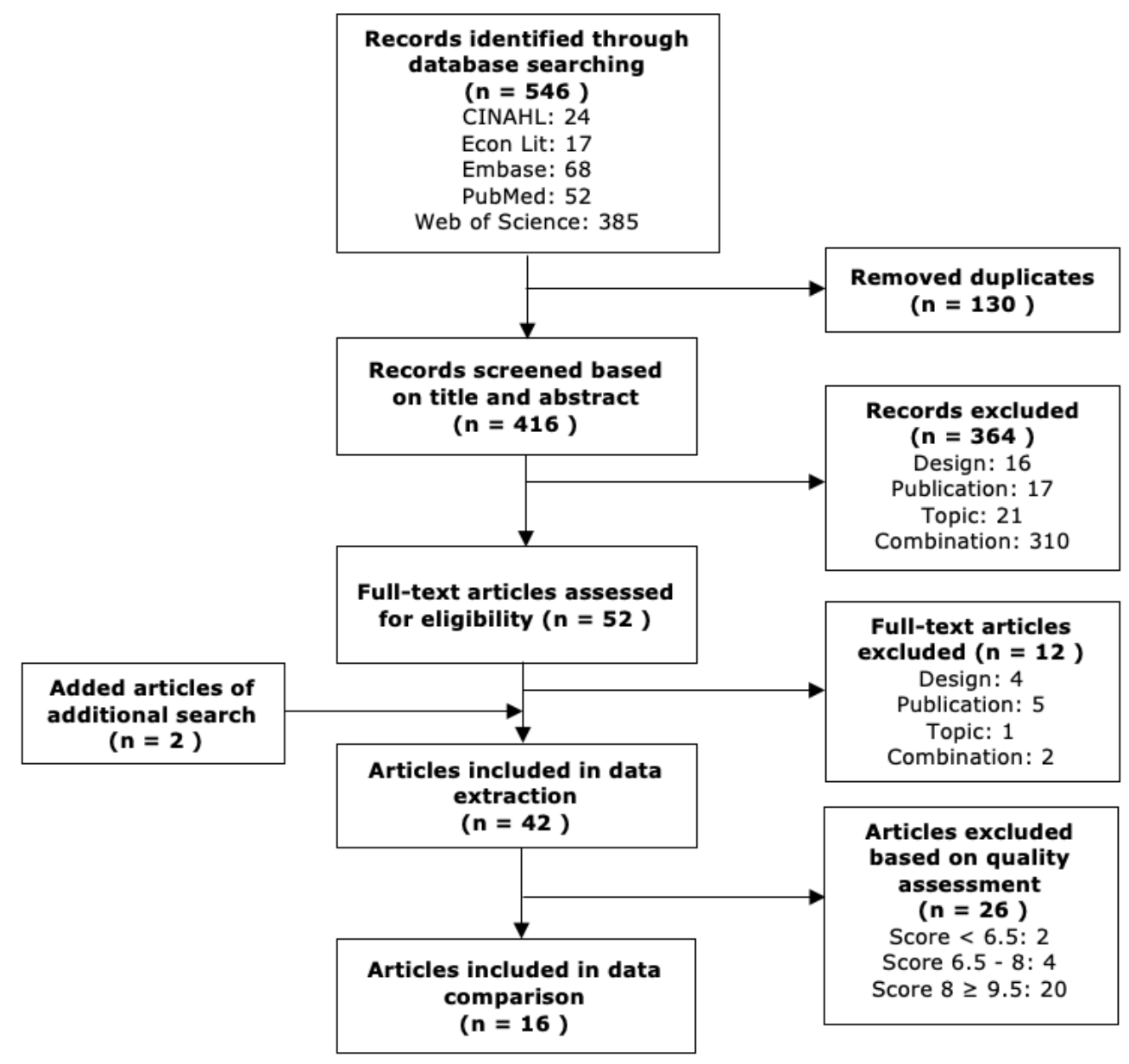

Figure 1

PRISMA flow diagram of choice-based experiments capturing vaccine preferences 


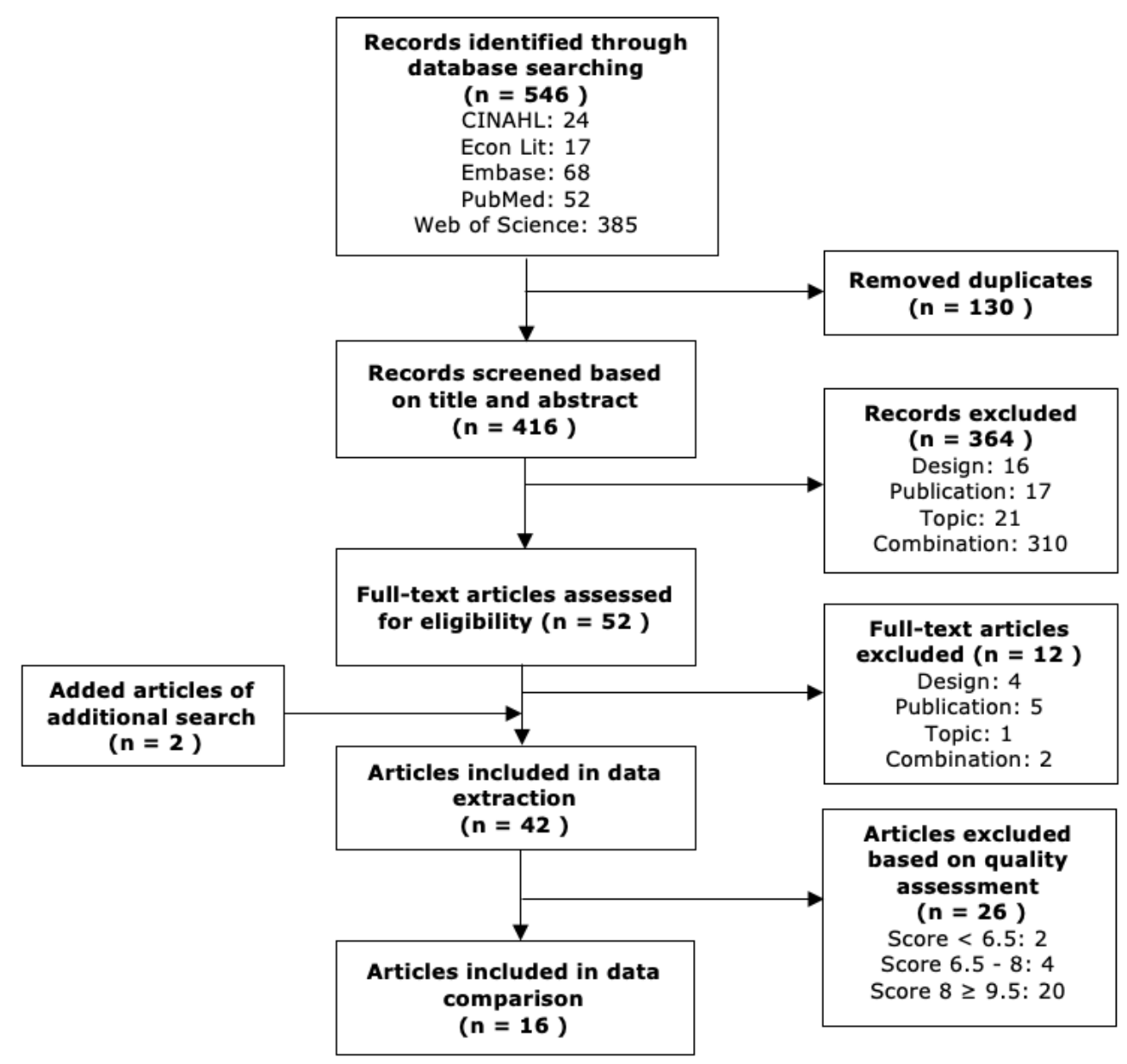

Figure 1

PRISMA flow diagram of choice-based experiments capturing vaccine preferences

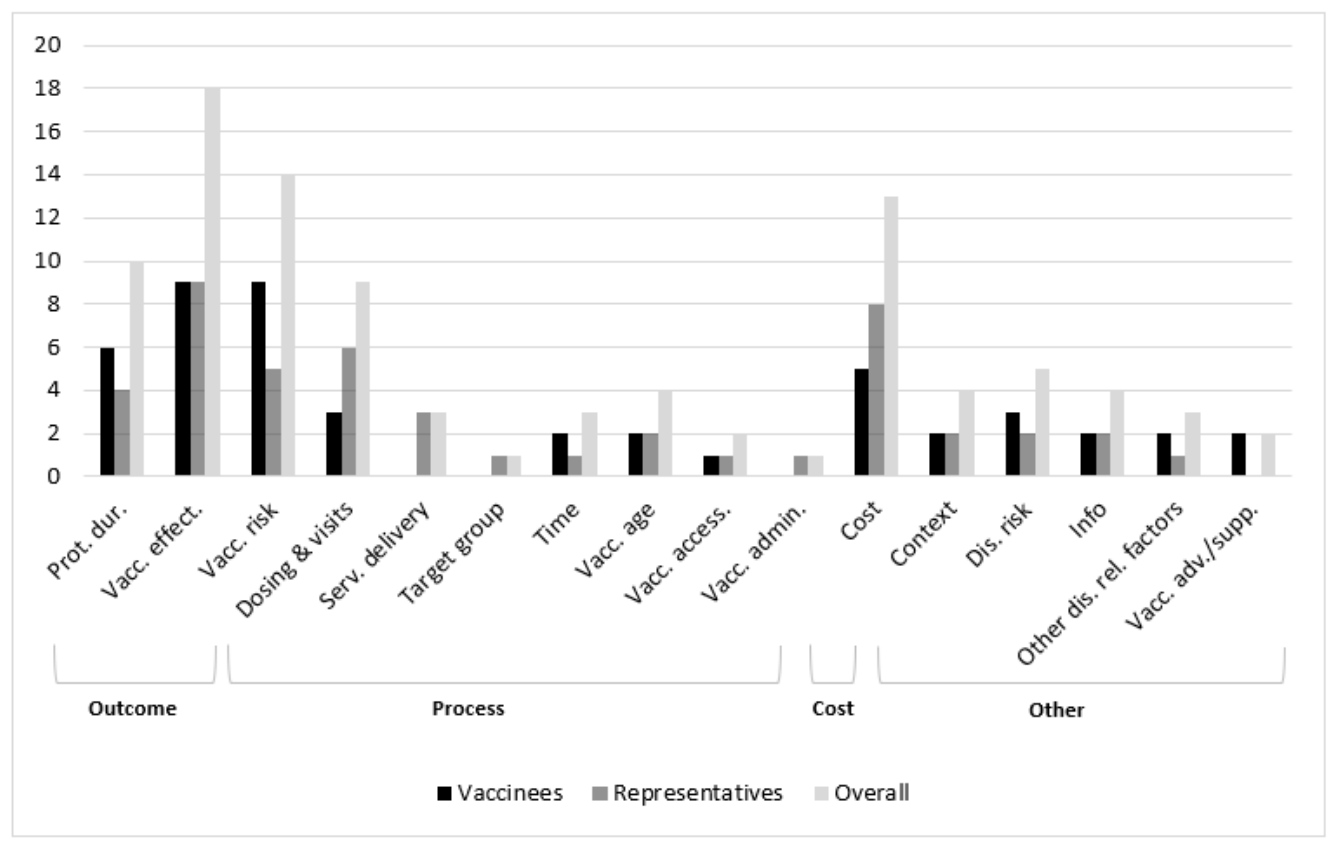

Figure 2

Frequency of domains in high-quality studies 


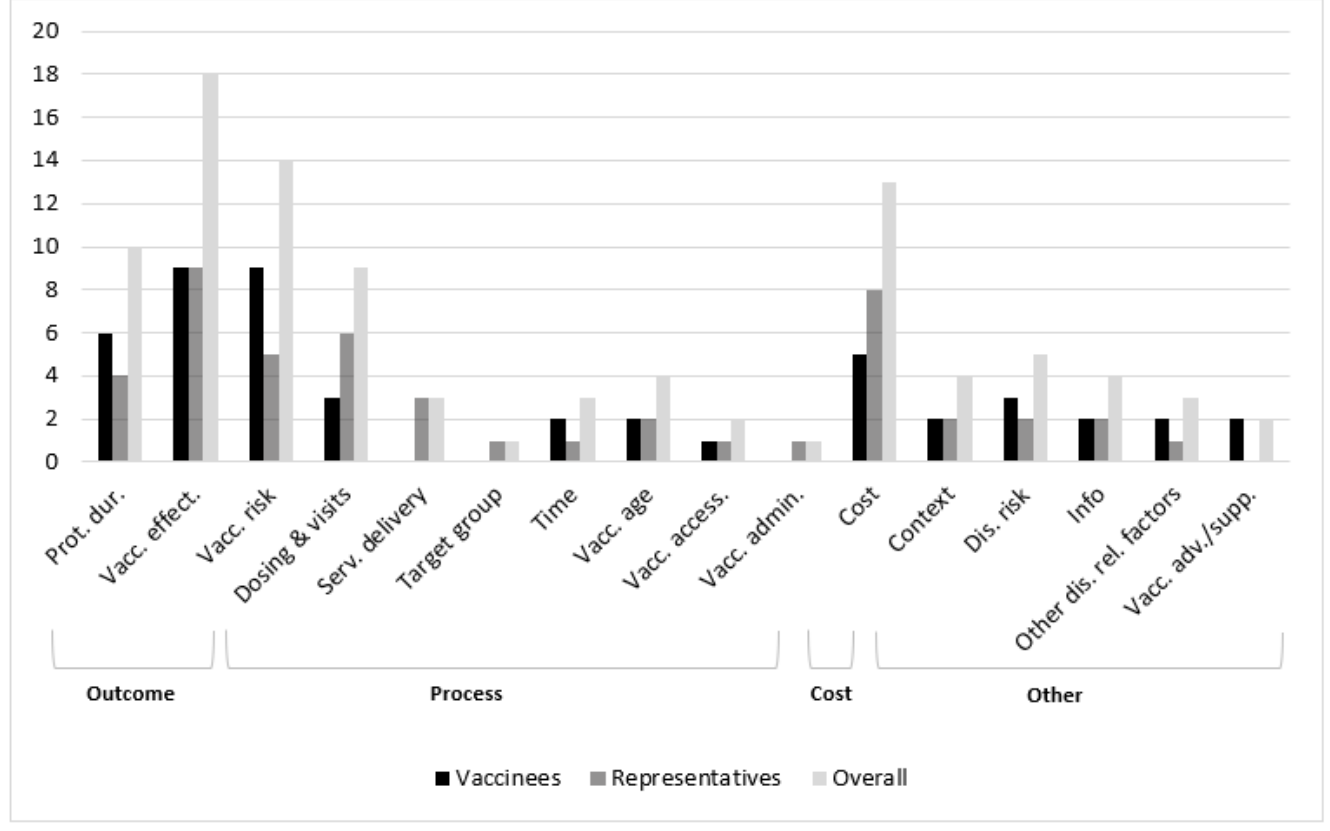

\section{Figure 2}

Frequency of domains in high-quality studies

\section{Supplementary Files}

This is a list of supplementary files associated with this preprint. Click to download.

- Additionalfile1.docx

- Additionalfile1.docx

- Additionalfile1.docx

- Additionalfile2.docx

- Additionalfile2.docx

- Additionalfile2.docx

- Additionalfile3.docx

- Additionalfile3.docx

- Additionalfile4.docx

- Additionalfile4.docx

- Additionalfile4.docx

- Additionalfile5.docx

- Additionalfile5.docx

- Additionalfile6.docx

- Additionalfile6.docx

- Additionalfile6.docx

- Additionalfile7.docx

- Additionalfile7.docx

- Additionalfile7.docx

- Additionalfile8.docx

- Additionalfile8.docx 